\title{
La influencia latino-románica en la estructura morfológica nominal de la lengua vasca
}

\author{
The Latin and Roman influence in the nominal \\ morphological structure of the Basque language
}

José Fernando Domene Verdú

RESUMEN: La influencia latina y romance fue muy importante en la lengua vasca. El sufijo nominal y abundancial vasco -eta es de origen latino y el artículo enclítico vasco - $a$ se formó por influencia del artículo románico, a partir de la utilización del demostrativo de $3^{\text {er }}$ grado como artículo determinado. En este artículo se exponen ampliamente las consecuencias de esa influencia latino-románica en la declinación vasca y se reconstruye el proceso de formación de la declinación definida y de las dos declinaciones de plural a partir de la integración de esos dos morfemas.

Palabras clave: estructura morfológica nominal, declinación, influencia lingüística, proceso de formación, reconstrucción lingüística, artículo, pronombre.

ABSTRACT: Latin and roman influence in the basque language was very important. The basque nominal and abundantial suffix - eta has a latin origin and the basque clitic article $-a$ is a loan translation of the romanic one by using the $3^{\text {rd }}$ person demonstrative as a determinated article. The consequences of this influence in basque declension and its dichronical process are explained broadly and proofly in this article, reconstructing the whole formation process of the basque determinated declensions and the two basque plural declensions after this latin and romanic influence.

Keywords: nominal morphological structure, declension, linguistic influence, formation process, linguistic reconstruction, article, pronoun. 


\section{INTRODUCCIÓN}

El objetivo de este artículo es exponer la importantísima influencia que el latín y, después, el romance ejerció sobre una parte muy concreta de la gramática de la lengua vasca, como es su compleja declinación o estructura morfológica nominal $(E M N)^{1}$. La lengua vasca es de tipo aglutinante ${ }^{2} y$, por ello, tenía una EMN con un gran número de casos (ya que incluía los casos locativos, que en las lenguas flexivas se expresan por medio de las preposiciones), pero era a su vez enormemente regular, ya que había una única declinación (indefinida) para todos los sustantivos, adjetivos y pronombres (vid. Domene, 2011: 158). La vecina lengua celtibérica pudo influir en esa primitiva EMN (posiblemente en el caso genitivo locativo, con sufijo $-k o$ ), pero la influencia del latín, y después del romance, fue decisiva en la EMN vasca, ya que permitiría la aparición de dos casos más (el partitivo y el adlativo indefinido) y, sobre todo, del artículo (definido y enclítico) y del número (plural), lo que supuso la formación de tres declinaciones más (la definida, la de plural próximo y la de plural lejano), que se añadieron a la primitiva declinación indefinida. El tratamiento de respeto vasco, además, fue en todo paralelo al de las lenguas románicas y otras lenguas europeas. Estos procesos lingüísticos son los que se exponen a continuación. Primero, añalizaremos el origen latino del sufijo vasco -eta y su papel en la fomación de las dos declinaciones plurales. Después, la influencia romance en los artículos enclíticos vascos $-a$ y $-o$, y su papel en la fomación de la declinación definida y la declinación de plural cercano, respectivamente. Pero hemos intentado llegar más lejos, ya que el análisis de esta influencia latino-románica en la EMN vasca, una vez analizado el origen de estos elementos, permite reconstruir con detalle todo el proceso de formación y desarrollo de las cuatro declinaciones actuales a partir de la primitiva declinación indefinida anterior a la romanización, pudiéndose establecer así, en orden cronológico, las sucesivas fases que han seguido los distintos cambios que han originado la actual EMN y

\footnotetext{
${ }^{1}$ La influencia del latín y el romance sobre la conjugación vasca fue igual de importante, porque permite comprender la formación de la estructura analítica de la misma (formada por el verbo principal en participio más el verbo auxiliar), que con el trascurso del tiempo se ha convertido en la mayoritaria en la gramática de la lengua vasca (Domene, 2010), hasta el punto de que la antigua estructura sintética solo se ha conservado de manera residual en un escaso número de verbos (entre ellos los auxiliares).

${ }^{2}$ En las lenguas aglutinantes, los morfemas indican las diferentes funciones sintácticas y gramaticales por adición ordenada de distintos morfos, cada uno de los cuales representa a un único morfema. Por ello, la ausencia de sincretismo hace que aumente considerablemente el número de unidades morfológicas y, proporcionalmente, la regularidad de todo el sistema. La lengua vasca es, por tanto, especialmente adecuada para la aplicación del método de reconstrucción interna por la riqueza y complejidad de su morfología, debido a su carácter aglutinante (vid. Domene, 2009: 254-267).
} 
su evolución a partir de la influencia latino-románica. Se trata, pues, de aplicar en este artículo el método de reconstrucción interna, que es el único que permite conocer el pasado de una lengua genéticamente aislada antes de los primeros textos escritos ${ }^{3}$, y el proceso reconstruido confirmará la validez de todo lo expuesto en los apartados anteriores.

\section{LA INFLUENCIA LATINA Y EL SUFIJO COLECTIVO -ETA}

Como consecuencia de la conquista romana, se produjo un contacto de lenguas y una influencia lingüística entre el vasco y el latín vulgar, primero, y el romance después. La vecindad y la situación de diglosia amplia favorecieron la influencia del latín sobre el vasco (Caro, 1945; Michelena, 1985 [1961]; 1987 [1974]). Ya en la Edad Media, habría una influencia mutua entre el romance y el vasco ${ }^{4}$ (Gimeno, 2006; Gimeno y García Turza, 2010: 165-184), al menos hasta que el castellano se normalizó en los textos escritos (Gimeno y García Turza, 2010: 179-181) y se convirtió en lengua oficial y de prestigio a partir del siglo XIII. Finalmente, la consolidación del castellano, del occitano y del francés como lenguas de prestigio favoreció la influencia de esas lenguas románicas sobre el vasco 5 .

La influencia latina fue general en la lengua vasca (vid. Domene, 2010) y afectó también a la estructura morfológica nominal (EMN) o declinación (vid. Azkarate y Altuna, 2001: 81-135). En los casos locativos, hay dos sufijos de género a los que se añaden los sufijos casuales: el sufijo -gan (< gain = 'encima'; vid. Trask, 1997: 203; Azkarate y Altuna, 2001: 120), que indica el género animado, y el sufijo - $t a-$, que indica el género inanimado. El sufijo - $t a$ - es moderno $^{6}$ y procede del sufijo derivativo - eta de los topónimos, que a su vez procede del sufijo abundancial latino -ĒTUM, cuyo plural es -ĒTA por ser neu-

\footnotetext{
${ }^{3}$ El primer libro en vasco, Linguae Vasconum Primitiae de B. Dechepare, fue editado en 1545.

4 "Desde la primera mitad del siglo VIII, el contexto social y cultural de la Galia y del Occidente románico correspondería a una situación general de diglosia románica (estricta en un principio y amplia posteriormente). La variedad normalizada sería el latín medieval, usado como registro escrito y oral formal, y los romances serían las variedades orales familiares e informales (francés, occitano, catalán, navarro, aragonés, italiano, asturiano, leonés, mozárabe y gallego" (Gimeno, 2006: 62; Gimeno y García Turza, 2010: 165).

${ }^{5}$ La influencia de la lengua vasca en castellano es de sobra conocida (Lapesa, 1981 [1942]: 35-50; Echenique, 1987, 1997, 2005; Echenique y Sánchez, 2006; etc.), y también ha sido estudiada la influencia latina y romance en vasco, sobre todo en el léxico y en la fonología (Caro, 1945; Michelena, 1985 [1961]; 1987 [1974]; Echenique, 1987, 1997; Domene, 2011: 60-118; etc.), aunque no tanto en la morfología nominal y verbal (Domene, 2007a; 2010; 2011: 187-199; etc.).

${ }^{6}$ En suletino, se ha documentado etxe- $n=$ 'en la casa', en vez de etxe-ta- $n$, que es lo que P. Lafitte (1995 [1944]: 59) denominó "inessif archaïque".
} 
tro. Fue H. Schuchardt (1922: 74) quien propuso el origen del sufijo -eta en el sufijo abundancial latino neutro -ĒTU(M), cuyo plural es -ĒTA, y con esa misma función de se ha conservado en el sufijo - eta frecuente en la toponimia vasca como sufijo abundancial ${ }^{7}$ (por ejemplo, Harri-eta $=$ 'pedregal', Pago-eta $=$ 'hayedo', etc.), de forma paralela al sufijo abundancial románico -edo / -eda (por ejemplo, olm-edo, hay-edo, cerec-eda, alam-eda, pin-edo/pin-eda, avellaneda, salc-edo, viñ-edo, robl-edo, etc.). $\mathrm{M}^{\mathrm{a}} \mathrm{D}$. Gordón (2010) ha demostrado que este sufijo colectivo latino ${ }^{8}$ fue muy abundante en la toponimia de la Península Ibérica, sobre todo en su parte meridional, lo que prueba la vitalidad que llegó a alcanzar en las áreas alejadas del centro del Imperio en la baja latinidad. El sufijo - eta formó parte de algún gentilicio latino como bardy-eta-i (que alterna con vard-ul-i, en la actual Guipúzcoa y en la parte oriental de Álava), o turboleta (del topónimo Turb-ul-a, Teruel, procedente de Turba más el sufijo diminutivo latino -ul-). Un compuesto de -eta, el sufijo -etan- $>$-tan-, formado por los sufijos latinos -eta y -an-, formó la mayoría de los gentilicios del área lingüística de la Península que aportan las fuentes latinas (iacc-etan-i, sed-etan-i, suess-etan-i, cer-etan-i/cerr-etan-i, indic-etan-orum, aus-etan-i, lai-etan- $i$, lacetan-i, coss-etan-i, lob-etan-i, constes-tan-i, ed-etan-i, dei-tan-i, basti-tan-i/bastetan- $i$ y turd-etan-i, que alterna con turd-ul-i) y también algunos de otras áreas lingüísticas prerromanas (lusi-tan-i, carp-etan-i, or-etan-i, aqui-tan-i, mauretan-i / mauri-tan-i, etc.). E. Nieto Ballester (1999) ha demostrado la pervivencia del sufijo colectivo latino -ĒTU(M) / -ĒTA en abundantes topónimos actuales y de su antigüedad, ya que "de différents détails de phonétique historique, aussi de l'histoire du lexique peuvent souvent nous indiquer que nous sommes face à toponymie latine, pas romane" (Nieto, 1999: 142). El sufijo -eta-, en efecto, se tuvo que introducir en vasco antes del siglo $\mathrm{V}$ porque ha conservado la oclusiva sorda intervocálica y la sonorización de las oclusivas sordas intervocálicas se

7 "En un tiempo en que el desarrollo del artículo (pospuesto) en vasco no había aún completado su ciclo, invadió aquí del latín el sufijo colectivo -ĒTUM, más bien en plural -ĒTA, y así se estabilizó, ej.: mendi 'monte, plural mendieta 'montañas', 'sierra', por lo menos en locativos" (Schuchardt, 1947 [1923]: 46): mendi-n 'in monte', mendi-eta-n 'in montibus'; mendi-tik 'a monte', mendi-eta-tik 'a montibus'; mendi-ra 'ad monte', mendi-eta-ra 'ad montibus'.

${ }^{8}$ Existe un sufijo -ta/-da en los topónimos ibéricos (en ILTiŔ-Ta / Iler-da, Ede-ta, BeNKoTa, Tur-da, Arun-da, Gerun-da, Mun-da, Osicer-da, etc.), que alterna con -ke/-ge (en ILTiŔ-KeSKeN / iler-ge-te-s; INDi-Ke-SKeN / UNDi-Ke-SKeN / indi-ce-te-s / indi-ge-te-s, etc.) y con -te (en ILTiŔ-Te) (vid. Luján, 2005: 480-484) y ese sufijo -tal-da podría explicar el uso tan frecuente del sufijo latino -eta en el área lingüística ibérica debido al parecido entre ambos. Sin embargo, ni el sufijo ibérico - $t a /$-da de los topónimos ni el sufijo latino abundancial o colectivo -eta aparecen en los gentilicios en escritura ibérica, en los que el sufijo indígena utilizado era -SKeN. Además, el sufijo vasco -ta-, propio de los casos locativos inanimados de la EMN indefinida, es moderno y procede del sufijo de plural -eta de los casos locativos inanimados. Por lo tanto, parece difícil la relación entre el sufijo ibérico - $t a /$ - da y el vasco - $t a$ o el latino -eta, aunque es significativo el uso tan abundante de este último en el área lingüística ibérica. 
habría producido en el latín vulgar de la Romania occidental antes del siglo V, puesto que ya se documenta en las inscripciones en la época imperial (Lapesa, 1981 [1942]: 77). Ya R. Ménendez Pidal (2007: 341-350) y V. Väänänen (1988 [1968]: 213-214) se ocuparon de la sonorización de las oclusivas, y C. Pensado Ruiz (1984: 193-204) dio una visión muy completa del estado de la cuestión sobre la cronología de dicho fenómeno?.

Una vez introducido en vasco, el sufijo - eta se utilizó como sufijo abundancial, igual que el sufijo autóctono -aga (harri-eta es sinónimo de harri-aga = 'pedregal'), y se declinó en los casos locativos de la EMN para expresar el plural. Al principio, sería el singular de un sustantivo abundancial (harri-eta- $n=$ 'en el pedregal', harri-eta-ra = 'al pedregal', harri-eta-tik = 'desde el pedregal', harri-eta$k o=$ 'del pedregal', etc.), y así se ha conservado en los topónimos, pero al utilizarse también con otros sustantivos que no tenían ese significado abundancial, pasó a expresar el plural de los casos locativos ${ }^{10}$ (zubi-eta- $n=$ 'en los puentes', zubieta-ra = 'a los puentes', zubi-eta-tik = 'desde los puentes', zubi-eta-ko = 'de los puentes', etc., y después harri-eta- $n=$ 'en las piedras', etc.). Pero, entonces, la /e/ del sufijo - eta- se interpretó como un sufijo de plural, quizá por analogía con el sufijo de plural - $e$ de la estructura morfológica verbal (EMV) o conjugación, para establecer la concordancia con ella. Entonces, ya en época muy tardía (a finales de la Edad Media o ya en la Edad Moderna), -ta- se identificaría, por falso análisis, como un sufijo de los casos locativos inanimados (harri-eta- $n>$ harri-e-ta- $n$ $=$ 'en las piedras'), porque eran los casos en los que se utilizaba el sufijo -eta del que procedía. Consecuentemente, se añadió después ese nuevo sufijo -ta- (ya sin la /e/ de -eta) a los casos locativos inanimados de la EMN singular indefinida como

\footnotetext{
${ }^{9}$ Sobre su cronología, es necesario aclarar que el debilitamiento de las consonantes intervocálicas, mediante el cual las oclusivas sordas se sonorizan y las sonoras se fricatizan e incluso desaparecen, ocurrió a partir del siglo VI, pero solo en la Romania occidental, ya que en italiano central y meridional y en rumano se han conservado las oclusivas originales. Sin embargo, en la época imperial ya se documenta este cambio fonético en las inscripciones (Herman, 1997 [1975]: 55-58; Lapesa, 1981 [1942]: 77), por lo que, en el latín vulgar, la sonorización de las oclusivas intervocálicas se habría producido antes del siglo V, y su fricatización o desaparición, en del siglo III (Quilis, 2003: 52-53). "Cronológicamente, los primeros ejemplos, aislados por otra parte, se encuentran en Pompeya: 5380 tridicum, 8830 tridici = triticum, tritici $[\ldots]$ ", aunque "los préstamos latinos del germánico parecen indicar que la sonorización no ha podido realizarse, al menos en la Galia, antes del siglo V" (Väänänen, 1988 [1968]: 113). "En líneas generales hay testimonios aislados de sonorización desde bastante pronto en varios lugares de la Romania (p. ej. cartas de Claudio Terenciano del ca. 115 d.C.), aunque una generalización de testimonios escritos con resultados sonoros no se da hasta el siglo VII. Wartburg es partidario del comienzo del fenómeno hacia el siglo III d.C. Richter lo sitúa entre el s. III y v d.C. Bustos cree que tiene alguna generalidad a partir del s. IV y la mayoría lo sitúa en el s. V d. C.” (Gorrochategui, 2009: 550).

${ }^{10}$ Así, 'de parejas como biku 'higuera', bikueta 'higueras', bagu 'haya', bagueta 'hayedo', etc., se asignó a -eta- el valor plural” (Castaños, 1979: 52).
} 
un nuevo sufijo que indicaba los casos locativos del género inanimado ${ }^{11}$. Por ejemplo, etxe- $n=$ 'en casa', que se ha documentado en suletino (Lafitte, 1944: 59), se convirtió en etxe-ta- $n$ (Schuchardt, 1947 [1923]: 46), *harri- $n$ en harri-ta- $n=$ 'en piedra', etc.

De la misma manera (y posiblemente por analogía con -ta-), el adverbio gain = 'encima' se añadió de forma enclítica en los casos locativos del género animado (Azkue, 1969 [1905-1906]; Trask, 1997: 203; Azkarate y Altuna, 2001: 120) como un nuevo sufijo (-gan) que indicaba esa misma función y se añadía al sustantivo en genitivo posesivo definido ${ }^{12}$. Así, por ejemplo, gizon-aren gain = 'encima del hombre' se convertiría en gizon-aren-gan = 'en el hombre', y sobre este caso inesivo se formaron todos los demás casos locativos animados añadiéndole los sufijos correspondientes: gizon-aren-gan- $a$ = 'al hombre', gizonaren-gan-dik $=$ 'desde el hombre', etc.

Mediante el sufijo - eta, también se formó la EMN plural de los demostrativos, que se utilizaban en vez de los inexistentes pronombres de $3^{\mathrm{a}}$ persona ${ }^{13}$. El sufijo - eta sería, por tanto, un procedimiento primitivo de formación del plural, anterior a la generalización del artículo enclítico.

\section{LA INFLUENCIA ROMANCE Y EL ARTÍCULO DEFINIDO ENCLÍTICO VASCO}

Según Azkue (1969 [1923-1925]: I, 1), antiguamente solo existirían dos demostrativos, $o=$ 'este/esta/esto y ese/esa/eso' y $a=$ 'aquel/aquella/aquello'.

${ }^{11}$ La declinación vasca sin el sufijo -eta- se ha conservado, en efecto, solamente en los adverbios de lugar, que proceden de los demostrativos y han conservado su antigua EMN en algunas variantes dialectales: el adverbio on- $a$ / hon- $a=$ 'aquí (indicando movimiento)' frente al demostrativo hon-ta-ra / hon-e-ta-ra = 'a este/esta/esto'; el adverbio orr-a / horr-a = 'ahí (indicando movimiento)' frente al demostrativo hor-ta-ra / horr-e-ta-ra = 'a ese/esa/eso'; el adverbio $a-n$ / $h a-n=$ 'allí' y $a-r a / h a r-a(t)=$ 'allí (indicando movimiento)' frente al demostrativo ar-ta-n / har-ta- $n=$ 'en aquel/aquella/aquello' y ar-ta-ra / har-ta-ra(t) = 'a aquel/aquella/aquello'.

${ }^{12}$ Teniendo en cuenta que en el dialecto occidental o vizcaíno se conserva la variante -gain$a$ del caso alativo directivo en vez de la general -gan-a en los casos locativos animados, el sufijo original de dichos casos sería el adverbio de lugar enclítico gain = 'encima' (Trask, 1997: 203; Azkarate y Altuna, 2001: 120). El adverbio gain evolucionó fonéticamente a -gan en el dialecto occidental o vizcaíno, con reducción del diptongo $(a i>a)$, y a gañ en suletino, con palatalización de /n/ tras /i/ (gain > gañ). Estos cambios también han ocurrido en el sufijo de los locativos animados: -gan- $a$ la variante gañ- $a>$ gañ-e (amagañe = 'a la madre') (Azcarate y Altuna, 2001: 119). Así, por ejemplo, seme-a-gain > seme-a-gan = 'encima del hijo' pasó a significar 'en el hijo', sustituyendo posiblemente a *seme-ta-n, que dejó de utilizarse.

${ }^{13}$ Más tarde, se utilizaron también otros procedimientos para distinguir el singular y el plural en los demostrativos, como es la utilización en los casos oblicuos de una raíz diferente en singular y en plural (hon- y hau- en el demostrativo de $1^{\text {er }}$ grado, horr- y hori- en el de $2^{\circ}$, y har- y $h a$ - en el de $3^{\circ}$, respectivamente). Las raíces utilizadas en el plural son las mismas que las del caso nominativo o absolutivo singular, y proceden de las antiguas raíces de los dos demostrativos primitivos (Domene, 2011: 152-157, 159-160). 
Después, el demostrativo de proximidad se desdoblaría en dos, originándose los tres demostrativos actuales, que en el caso nominativo o absolutivo son hau= 'este/esta/esto', hori = 'ese/esa/eso' y hura = 'aquel/aquella/aquello', aunque en el dialecto occidental o vizcaíno se ha conservado el primitivo demostrativo $a$ = 'aquel/aquella/aquello' frente al más moderno ura / hura de los demás dialectos ${ }^{14}$. Los dos demostrativos primitivos, $o$ y $a$, se habrían conservado solo en los artículos enclíticos de la EMN definida y la EMN de plural próximo de los sustantivos y adjetivos. El primitivo demostrativo o existía todavía en la Edad Media junto al demostrativo $a$ y está suficientemente documentado como artículo enclítico (muskarr-o, çuurr-o / çuurr-a, moç-o / motç-a, çaldun-o / çaldun-a, Hederr-o / Hederr-a, Sagarr-o / Sagarr-a/Sagar, Gogorr-o, Hudal-o, Gorostapal-o, etc.; vid. Azkarate y Altuna, 2001: 41), pero después se modificó para diferenciarse de ese artículo enclítico - $o$. Su EMN primitiva se ha conservado prácticamente intacta en la EMN definida de los sustantivos y adjetivos y en las dos EMN de plural próximo, ya que los sufijos casuales de esas EMN apenas han sufrido modificaciones, salvo la adición del sufijo - $t a$ - en los casos locativos.

El sufijo determinativo - $a$ es en realidad el artículo enclítico y apareció en vasco por influencia románica y por imitación del artículo románico ${ }^{15}$, que no era más que el pronombre demostrativo de $3^{\text {er }}$ grado singular, igual que ocurre en vasco (Azkarate y Altuna, 2001: 11-46). En efecto, “el latín clásico carecía de artículos, pero en el latín vulgar el demostrativo de $3^{\mathrm{a}}$ persona (ILLE, ILLA, ILLUD) comenzó a adquirir este valor" (Torrens, 2007: 93). Esta innovación apareció en romance, en la lengua escrita, después del siglo v, ya que "se observa ciertamente, sobre todo tras la caída del Imperio, un crecimiento masivo de la frecuencia de ille e ipse" y, además, "ille sobrevive como pronombre personal de tercera persona, pero es también el punto de partida del futuro artículo

\footnotetext{
${ }^{14}$ No hay unanimidad en el origen de los demostrativos vascos. Por eso, es necesario aclarar que el demostrativo $o$ puede ser el primitivo demostrativo de $3^{\text {er }}$ grado, según la hipótesis de Azkue (1969 [1905-1906]), o puede proceder, fonéticamente hablando, de hauek $>$ hoek $>$ hok > $o k=$ 'estos/estas' (el plural del demostrativo próximo actual haur), mediante el CF $=a u>o$, según la hipótesis de Michelena e Irigoyen (vid. Azkarate y Altuna, 2001: 20-42). Sin embargo, esta compleja evolución fonética indica su modernidad y se contradice con la antigüedad del artículo enclítico $o$, que se utilizó en la EMN vasca antes del siglo X, era de uso corriente en la Edad Media porque se documenta en los textos medievales y en la literatura antigua, que empieza en el siglo XV, desapareció al principio de la Edad Moderna y ya no existía en el siglo XVIII. Habría que aceptar, por tanto, la hipótesis de Azkue (dos demostrativos primitivos $o$ y $a$ ) y considerar que los demostrativos actuales se han desarrollado a partir de ellos más tarde, en todas sus variantes, incluso con la adición posterior de [-r] en los dialectos septentrionales (hau-r, o-r / ho$r$-, a-r / ha-r-, igual que ocurriría en hiru-r, lau-r, etc.) (vid. Domene, 2011: 143-157).

15 "El artículo no existía en la lengua latina; solo en su última época, el latín vulgar sintió la necesidad de hacerse con un artículo como el griego, y se lo creó de diversas maneras en los diversos territorios" (Menéndez, 1987 [1904]: 260).
} 
en romance" (Herman, 1997 [1975]: 81-82) ${ }^{16}$. En el latín tardío (vid. Lapesa, 2000 [1961]; 1981 [1942]: 71), "en la Península Ibérica hay casos evidentes de artículo en sintagmas en los cuales el sustantivo se aduce por primera vez -uso no anafórico- y que datan del siglo vII" (Alvar y Poittier, 1983: 111) 17, y "la fecha del siglo VIII asignada por Muller y Pei a la extensión del artículo en la Francia merovingia ha de entenderse válida para una etapa muy adelantada: el artículo estaba entonces tan consolidado en el habla, que la lengua escrita ya no acertaba a evitarlo" (Lapesa, 2000 [1961]: 368-369) ${ }^{18}$.

El artículo enclítico vasco también apareció por la utilización del pronombre demostrativo de $3^{\text {er }}$ grado $a / h a=$ 'aquél/aquella/aquello', igual que en romance, solo que de forma enclítica (Tovar, 1950: 54), como sufijo - $a$, de manera que el antiguo demostrativo solo se ha conservado en el dialecto occidental o vizcaíno. Pero su aparición en vasco es más tardía que en las lenguas románicas. En efecto, no aparece en ninguno de los antropónimos de las inscripciones aquitanas de época romana (HARBELEX, BELEX, CisON, SEME, ANDERE, NESKATO, etc.) y otros no fueron declinados con el sufijo - $a$ (ILUNI, ASTO, ILUNNO, etc.). El artículo vasco aparece por primera vez en apelativos empleados como nombres propios en la Edad Media, a partir del siglo X precisamente, como Ozoa (= Ochoa = 'el lobo') en el año 950, Obeko Zuria (zuria = 'el blanco') en el año 1106 y el Monasterio de Varría (Barria = 'el nuevo') en el año 1053 (Caro Baroja, 1945: 158-164). En los topónimos de la Reja de San Millán (s. XI), el artículo es -ha porque todavía conserva la /h/ del antiguo demostrativo $h a=$ 'aquél/aquella/aquello' (Manterola, 2006).

${ }^{16}$ Sobre la cronología del origen del artículo, es necesario aclarar que "le paradigma apocopé est attribué à la langue parlée 'dès le IVe siècle'. Il est traité comme étant déjà un article" (Banniard, 1995: 316), y antes de esa fecha el artículo indefinido, e incluso el numeral UNUS/ UNA/UNUM utilizado como artículo indeterminado, acompañando a los sustantivos que designaban cosas que no habían sido mencionadas antes, ya fue utilizado por Plauto en el siglo II a. C. (vid. Lapesa, 2000 [1961]; 1981 [1942]: 71). "Si es verdad que la creación de un artículo propiamente dicho, es decir, de un determinante que acompaña obligatoriamente al sustantivo, pertenece a la fase románica, no es menos verdad que está ya preanunciada desde el latín por ciertos usos debilitados de los demostrativos [...]. Por fin, ille e ipse anafóricos se hacen tan frecuentes en baja época que se puede hablar de un 'articuloide' [...]. El verdadero artículo aparece en la Parodia de la Lex Salica, de la segunda mitad del s. VIII: Et ipsa suppa frangant la tota, ab illo botiliario frangant lo cabo, at illo scanciono tollant lis potionis" (Väänänen, 1968: 214). En francés, en el "III ${ }^{-}-\mathrm{V}^{\mathrm{e}}$ siècle: ille dévient démonstratif faible; ecce ille dévient démonstratif fort"; en el " $\mathrm{VI}^{\mathrm{e}}-\mathrm{VIII}{ }^{\mathrm{e}}$ siècles: [...]", se da lo que él llama el "polymorphisme mérovingien", es decir, la coexistencia de ILLLE como demostrativo y como artículo; y finalmente, en el "IX ${ }^{\mathrm{e}}-\mathrm{XI}^{\mathrm{e}}$ siècles: $l i$ dévient article défini; cil dévient démonstratif" (Banniard, 1995: 319).

17 "Las pizarras visigóticas permiten aducir testimonios como 'at illa ammica tua oris dirige', 'ediciantur de cilla e de ilas auitaciones ejus', y en los documentos de los siglos VIII-XII las declaraciones orales abundan también en casos de ille, ipse, sin referencia a un sustantivo anterior, lo que hace pensar que ya no tenían carácter demostrativo." (Alvar y Pottier, 1983: 111). 
Pero no solo se utilizó como artículo el demostrativo de $3^{\text {er }}$ grado $a=$ 'aquel/aquella/aquello', sino también los de $1^{\circ}$ y $2^{\circ}$ grado, $a u=$ 'este/esta/esto' y ori $=$ 'ese/esa/eso', si bien el empleo de estos dos últimos solo se ha conservado en el dialecto occidental o vizcaíno (Altube, 1969: 46), porque en todos los demás dialectos han ido cayendo en desuso modernamente en favor del artículo procedente del demostrativo de $3^{\text {er }}$ grado a (Castaños, 1979: 164-165). "La existencia de varios artículos en una lengua hace posible una graduación de oposiciones en las referencias anafóricas y en las deícticas" (Castaños, 1979: 164-165): gizon- $a=$ 'el hombre (aquel)', gizon- $a u=$ 'el hombre (este)', gizonori $=$ 'el hombre (ese)', igual que en el romance primitivo, en el que también se utilizaban los tres demostrativos como artículos ${ }^{19}$, aunque después quedaron reducidos solamente a uno, el de $3^{\text {er }}$ grado, tanto en vasco $(-a)$ como en romance (ILLLE $>e l$ ), aunque en algunas áreas románicas prevaleció ǏPSE $>$ ese en vez de ILLLE ${ }^{20}$. El proceso se completó distinguiendo el demostrativo de $3^{\text {er }}$ grado del artículo determinado, que eran idénticos, de manera que el artículo conservó la forma original del antiguo demostrativo (ILLLE $>$ el), pero en el demostrativo se utilizó en latín vulgar la forma enfática de ǏLLE reforzada con ĒCCE > $* a c c u$ - añadido de forma proclítica (ĒCCE-ĬLLE $>* a c c u-\breve{l l l e}>$ aquel), que ya está documentada en Plauto ${ }^{21}$ (254 - 184 a. C.). En vasco, también se distin-

18 Así lo han expuesto, entre otros, Menéndez Pidal (1987: 260-261); Lapesa (1981 [1942], 2000 [1961], 2000 [1979]); Väänänen (1988: 213-214); Alvar y Poittier (1983: 110-115); Lathrop (1984: 144-145); Lloyd (1993: 262, 446-448); Orlandini (1992) o Penny (1993: 169-173). Más específicamente, Spevak (2008) ha estudiado los demostrativos is, hic e ille en Gregorio de Tours (siglo VI); Christol (1992) se ha ocupado del otro demostrativo que se utilizó como artículo determinado, ipse, en la Peregrinatio (siglo IV); González Ruiz (1993) y Banniard (1995) han expuesto el proceso de evolución del demostrativo ǏLLE hasta la creación del artículo en las lenguas románicas, es decir, entre los siglos III y VIII. Más recientemente, han tratado este mismo tema, entre otros, Rodríguez (2005: 126), en el bajo latín, y Gil (2005: 165), en el latín tardío o medieval.

${ }^{19}$ Para comprender bien este fenómeno, conviene recordar que "el artículo no es sino un demostrativo que determina un objeto más vagamente que los otros demostrativos, sin significación accesoria de cercanía ni alejamiento; sirve solo para señalar un individuo particular entre todos los que abarcaba la especie designada por el sustantivo; así que cualquier demostrativo pudo haber debilitado su significación y quedar con la vaga determinación de artículo. En la lengua antigua se usan en este sentido vago todos los demostrativos: 'mio Cid aguijó estos cavalleros quel sirven' (se refiere a los caballeros en general), "vayamos en aquel día de cras" (el día de mañana); “es día es salido e la noch entrada es'. Pero en general los romances se fijaron en el derivado de ille, salvo en Cerdeña, Gascuña, Ampurdán y Mallorca, donde prevaleció el de ipse (sa casa 'la casa')" (Menéndez, 1904: 260-261).

${ }^{20}$ En castellano, el demostrativo y el artículo, al menos en masculino, proceden del nominativo latino (ILLLE $>e l$ ), con el fin de distinguirlo del neutro (ILLUD $>l o$ ), porque en acusativo ambos se habrían confundido. En otras lenguas románicas vecinas, en cambio, el artículo masculino procede del acusativo latino (İLLUM > $l o>o$ ) (Väänänen, 1988: 215; Lapesa, 2000 [1961], 2000 [1979]; Mondéjar, 1985; Cano González, 1990; Frías, 1993). Para Alvar y Poittier (1983: 110115), en cambio, el origen del artículo masculino estaría en el acusativo también en castellano.

${ }^{21}$ Vid. Väänänen (1969: 216). "Junto a la serie normal, hubo otra serie enfática alargada con *accu $(<e c c e)$. Ya el latín coloquial había utilizado este recurso, según se acredita en Plauto 
guió el demostrativo del artículo definido en todos los dialectos excepto en occidental o vizcaíno ${ }^{22}$, utilizándose para ello el demostrativo de $3^{\text {er }}$ grado ura / hura (que podría ser el demostrativo a reforzado con $u r$ - / hur-) en todos los dialectos excepto en el occidental o vizcaíno, en el que el antiguo demostrativo $a$ se conservó idéntico al artículo enclítico. Por lo tanto, la aparición del artículo en romance es anterior y supone la cronología post quem para la del artículo vasco.

El empleo del antiguo demostrativo vasco $a=$ 'aquel/aquella/aquello' (que se conserva actualmente en el dialecto occidental o vizcaíno) como artículo enclítico se puede comprobar comparando la EMN definida de los sustantivos con la EMN del demostrativo de $3^{\text {er }}$ grado, tanto en singular ( $a$ / hura) como

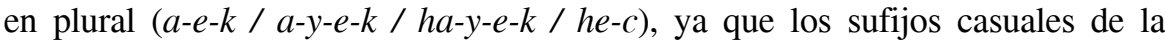
EMN definida de cada dialecto son los mismos que los demostrativos de ese mismo dialecto, solo que sin la /i/ epentética. Hay que tener en cuenta que el grupo vocálico [ae] del antiguo sufijo de ergativo plural $-a-e-k$ se contrajo en $/ \mathrm{a} /$ en el dialecto occidental o vizcaíno y en el central o guipuzcoano $(-a-e-k>$ $-a-k)$, en /e/ en el dialecto navarro y en el navarro-labortano $(-a-e-k>-e-k)$, y en [é] en roncalés y en suletino $(-a-e-k>e ́-k$ y $-a-e-n>-e ́-n)$, según las leyes fonéticas vascas (Michelena, 1985 [1961]: 117). En el demostrativo de $3^{\text {er }}$ grado, en cambio, a la variante $a-e-k=$ 'aquellos/as' evolucionó después de forma divergente, añadiéndosele una /i/ epentética para deshacer el hiato ( $a-e-k>$ $a-i-e-k>a-y-e-k)$, o bien con el cambio fonético $a e>e$, como en el demostrativo antiguo $h e-k$, he-i-e-n, he-i, etc. de los textos antiguos labortanos ${ }^{23}$ (vid. Castaños, 1979: 24). La necesidad de distinguir el demostrativo del artículo

("eccilum video", "eccistam video") o en la Peregrinatio ("ecce ista via, quam videtis", "ecce hic est in ducentis passibus")" (Alvar y Poittier, 1983: 107), lo que hizo que "en una época determinada, ille - convertido en signo de referencia anafórica - se apartara de su función demostrativa, que aún puede conservar alguna vez y, recíprocamente, que el carácter puramente demostrativo, con contenido pleno, con su significado preciso y no difuso, se refugiara en las formas enfáticas $($ ecce + ille)" (Alvar y Poittier, 1983: 112-113).

${ }^{22}$ Por lo tanto, "la tendencia analítica del romance, manifestada continuamente, ora por el uso de las preposiciones y el artículo en la flexión nominal y el empleo de los auxiliares haber y ser en la verbal" (Menéndez, 1987 [1904]: 4) está en el origen del uso del artículo, que empezó a producirse en la lengua hablada en el latín tardío e influyó en otras lenguas no románicas como el vasco.

${ }^{23}$ Debido a la actual diversidad dialectal y a su compleja evolución, es necesario indicar que la /h/ de los demostrativos se añadiría también posteriormente, igual que ocurrió en el pronombre de $2^{\mathrm{a}}$ persona singular ( $* g i>i>h i / y i=$ 'tú') y, como en este último, los demostrativos habrían perdido la /g/ inicial, antes de su utilización como artículos, en todos los dialectos excepto en los valles de Aezkoa, Salazar y El Roncal, aunque esa /g/ original se ensordeció en /k/ en Salazar y El Roncal. En efecto, como indicó Lafon (1995 [1943], I: 374), en los textos más antiguos publicados, que son del siglo XVI, "le préfixe de $2^{\mathrm{e}}$ pers. du sing. est, en principe, zéro chez Dechepare et Liçarrague, toute comme dans les textes biscayens". 
enclítico explicaría, posiblemente, que se añadiera esa /i/ epentética solo en el demostrativo $^{24}$ (en latín vulgar, el demostrativo ǏLLE también se había distinguido del artículo, pero añadiéndole ĒCCE $>* a c c u-$ ). Por tanto, en ergativo y en los demás casos, el plural se expresaría al añadirle directamente al lexema el

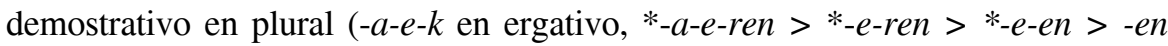
en genitivo posesivo; $*_{-} a-e-r i>*_{-} e-r-i$ en dativo, que evolucionó a $-e-r$ en suletino y a $-e-i$ en todos los demás dialectos; etc.). Y, a su vez, el plural del demostrativo se habría formado añadiéndole al singular el nuevo sufijo $-e$ - procedente del sufijo colectivo o abundancial de origen latino -eta- $(a+-e-+$ sufijos casuales) $)^{25}$.

También se añadió a los sustantivos el demostrativo próximo $o=$ 'este/esta/ esto y ese/esa/eso' de forma enclítica, tanto en singular, para formar la EMN definida próxima, como en plural ( $o-e-k=$ 'estos/estas y esos/esas'), para formar su EMN plural correspondiente, reduciendo a /o/ el grupo vocálico [oe] mediante el cambio fonético oe $>o(-o-k,-o-e-n,-o-i$, etc., igual que se documenta en el demostrativo septentrional ho-k, ho-e-n, ho-i, etc. ${ }^{26}$. Pero, entonces, la EMN de plural próximo se igualaría a la EMN de singular próximo, y por eso esta última cayó en desuso y desapareció. Ese sería el motivo de que solo se haya conservado la EMN próxima que expresaba el plural.

El nominativo plural, sin embargo, se formó siguiendo un procedimiento diferente al de los demás casos. Consistió en utilizar el ergativo singular (es decir, con el sufijo - $a k$ del singular, frente al sufijo -aek del plural, que evolucionó a -ak, -ek o -ék, según los dialectos), y por eso el sufijo de nominativo plural siempre es el mismo que el de ergativo singular y, en los dialectos occidental o vizcaíno y central o guipuzcoano, los sufijos de nominativo y de ergativo son idénticos en plural (-ak) porque -aek evolucionó a -ak en ergativo. Se trataría de un procedimiento primitivo para expresar el plural, anterior al que siguieron los demás casos (vid. Domene, 2011: 143-149).

${ }^{24}$ Es necesario indicar, sobre este aspecto, que la hipótesis de Gavel (1920) establecía el origen de esa /i/ y de esa / $\mathrm{k} /$ de la EMN plural en el sufijo - $k i$-, que habría perdido la /i/ manteniendo la $/ \mathrm{k} /$ en el dialecto occidental o vizcaíno y en el navarro, mientras que, por el contrario, habría perdido la $/ \mathrm{k} /$ manteniendo la /i/ en los demás dialectos. Sin embargo, hay que considerar que esta hipótesis es inaceptable porque la / $/ \mathrm{k}$ no desaparece en vasco entre vocales, por ley fonética (Michelena, 1985 [1961]: 234).

${ }^{25}$ Este procedimiento de formación del plural es más antiguo que el de añadir los sufijos casuales al nominativo plural con $-a k$, porque esos sufijos casuales también se añadieron al nominativo o al ergativo con sufijo $-e k$, que a su vez procedía de la contracción de - $a-e-k$ (por ejemplo, al añadirle el sufijo de genitivo posesivo $-e n$ al nominativo plural gizon-ak = 'los hombres', se formó gizon-ak-en = 'de los hombres').

${ }^{26}$ Este cambio fonético oe $>o$ cumple también las leyes fonéticas vascas, y Michelena (1985 [1961]: 120) cita expresamente este demostrativo ( $o-e-k=$ 'estos/estas y esos/esas') como ejemplo de dicho cambio fonético: "De o más $e$ : com. -ok, -on<-oek, -oen, en la declinación del artículo próximo". 
En el dialecto occidental o vizcaíno y en navarro meridional, se formó una nueva EMN de plural al añadirle los sufijos casuales a este sufijo $-a-k$ del nominativo plural para expresar el plural de los demás casos (de gizon-ak = 'los hombres', se formó gizon-ak-en = 'de los hombres', gizon-ak-i = 'a los hombres', gizon- $a k-a z=$ 'mediante los hombres', igual que ocurrió en los sustantivos inanimados como *gizon-ak-gan > gizon-ak-an = 'en el hombre', etc.). Este procedimiento es posterior a la desaparición de la [-a] final en la EMN y al consiguiente ensordecimiento de la oclusiva sonora $\left(-a-g a>*_{-} a-g>-a-k\right)$, según ley fonética (Michelena, 1985 [1961]: 131-133) 27.

En los casos locativos, sin embargo, no se utilizó el antiguo demostrativo plural como artículo determinado enclítico, igual que ocurría en el castellano medieval $^{28}$, sino que se ha conservado el procedimiento primitivo, consistente en la adición del sufijo abundancial latino -ĒTA (plural de -ĒTUM) seguido de los sufijos casuales propios de cada uno de los casos locativos (Schuchardt, 1947 [1923]: 46; Castaños, 1979: 66-67). Así, por ejemplo, para expresar el plural del caso inesivo harri-a- $n=$ 'en la piedra' se utilizó harri-eta- $n$, que es el caso inesivo singular del sustantivo harri-eta = 'pedregal' $\mathrm{y}$, por tanto, significa literalmente 'en el pedregal'. De ahí, se extendió el sufijo -eta- como sufijo de plural de los casos locativos a todas las demás palabras vascas declinables (por ejemplo, zubi-eta- $n=$ 'en los puentes', etc.). Por lo tanto, también tuvo que existir la EMN indefinida del plural, que utilizaría el sufijo abundancial -eta-, pero la /e/ desapareció detrás de la vocal final de los lexemas que le precedían, cuando éstos acababan en vocal, y después, detrás de todos los lexemas por analogía. A partir de entonces, la sílaba -ta- se interpretó como sufijo de locativo y, como consecuencia de ello, solo se añadió, moder-

27 También esta EMN plural formada a partir del sufijo - $a k$ es más moderna que la formada a partir de $-e$ - procedente del sufijo - eta-, ya que - $a k$ contiene el artículo determinado enclítico $-a$. Mientras que -eta- se tuvo que introducir en vasco antes del siglo $\mathrm{v}$, porque conserva la oclusiva sorda intervocálica (que se sonorizó en las lenguas románicas occidentales antes de esa fecha), el uso del demostrativo como artículo enclítico, por influencia del artículo románico, no se documenta en los topónimos vascos hasta el siglo X (Caro Baroja, 1945: 158-164; Manterola, 2006). El sufijo abundancial -aga, por lo tanto, sería más moderno que -eta porque es el mismo que se utilizó para expresar el plural del nominativo definido y, por tanto, contiene el artículo determinado enclítico $-a$, que procede del demostrativo de $3^{\text {er }}$ grado antiguo que se conserva en el dialecto occidental o vizcaíno. La [-a] final desapareció solamente en la EMN ensordeciendo la

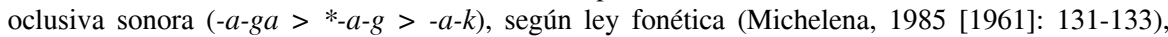
pero se conservó en el sufijo -aga de los topónimos (por ejemplo, harri-a-ga = 'pedregal', madari-a-ga = 'manzanal', pago-a-ga = 'hayedo', etc.).

28 Teniendo en cuenta que "no llevaban artículo en la Edad Media los sustantivos genéricos, colectivos, abstractos, frases preposicionales (en campo) y nombres de ríos" (Penny, 1993: 173), aquí estaría, posiblemente, la explicación de que no se añadiera el artículo enclítico en los casos locativos: la EMN vasca reflejaría el uso del artículo romance en la Edad Media. 
namente, en los casos locativos de la EMN indefinida singular (etxe- $n>$ etxeta- $n=$ 'en casa', etc.), ya que no aparece todavía en los textos más antiguos ${ }^{29}$.

\section{OTRAS INFLUENCIAS EN LA DECLINACIÓN VASCA}

La influencia románica también afectó a otros casos de la declinación, como el partitivo, que solo existe en la EMN indefinida, y el adlativo indefinido (Azkue, 1969 [1905-1906]: I, 47-48; 1969 [1923-1926]: I, 333).

El sufijo de ablativo -ik / $-r i k^{30}$ se utilizó en vasco para indicar el caso partitivo por influencia francesa ${ }^{31}$, española ${ }^{32} \mathrm{y}$, principalmente, occitana ${ }^{33}$, aunque en vasco solo se emplea con el objeto directo indefinido en las oraciones negativas, interrogativas y abstractas (por ejemplo, ogi-rik = '[algo] de pan',

${ }^{29}$ En suletino, se ha documentado etxe- $n=$ 'en la casa', en vez de etxe-ta- $n$, que es lo que P. Lafitte (1995 [1944]: 59) denominó "inessif archaïque": "L’inessif archaïque. - L'inessif indéfini ne devait pas comporter à l'origine d'affixe -ta-. Comme vestige de cet état de choses, quelques rares mots ont, à côté de la forme en -tan, une en - $n$ simple: Ex. etchen, 'à la maison (chez soi)'; ihizin 'à (la) chasse'; iraulden 'en train de labourer'; garraion, 'au charroi'; haintzurren 'en train de piocher'... Cet inessif a plutôt une valeur adverbial” (Lafitte, 1995 [1944]: 59).

${ }^{30}$ El sufijo $-i-k /-r-i-k$ procede del sufijo $-i /$ - $r i$ más el sufijo $-k a$ con la pérdida de /a/ final, como es normal en vasco. A su vez, el sufijo $-k$ procede de un antiguo sufijo $-c a$ documentado en los textos antiguos y añadido tanto al sufijo - $i$ - / - ri del partitivo como al sufijo - $d i$ / - $t i$ del perlativo (utilizado luego como ablativo), ya que el sufijo - $i-k /-r i-k$ aparece documentado como $-i$-ca / -ri-ca con la función de ablativo. Por ejemplo, pobreçarica yrtenica $=$ "salidos de la pobreza' en una poesía de 1610 en Pamplona. En los dialectos meridionales, el antiguo sufijo -di / - $t i$ del antiguo caso perlativo (lugar "por donde") más el sufijo $-k$, procedente de $-k a$, se utilizó como ablativo (lugar "desde donde"), sustituyendo al sufijo $-i-k /-r i-k$, que solo se ha conservado con esa función en los dialectos septentrionales y en algunas hablas de los meridionales.

${ }^{31}$ En francés, el artículo partitivo está formado por la preposición de más el artículo determinado (donne-moi du pain = 'dame pan' = 'dame [algo] del pan', je bois de la bière = 'bebo cerveza' = 'bebo [algo] de la cerveza', je mange des pommes $=$ 'como manzanas' = 'como [algo] de las manzanas'). En francés antiguo, en cambio, se utilizaba solo la preposición de, sin el artículo determinado.

${ }^{32}$ En español, también se utliza el partitivo de forma equivalente a como se utiliza en francés, aunque solo en determinadas situaciones: cuando el sustantivo va determinado por un demostrativo, un posesivo, un indefinido o una oración relativa (prenez de cette viande = 'tome de esta carne', mange de mon pain = 'come de mi pan', prends de l'autre fromage = 'coge del otro queso', il a bu du vin que je lui ai donné = 'bebió del vino que le había dado'); cuando en algunas frases, el partitivo hace resaltar la calidad de una cosa (pour ce qui est du vin j'en ai bu et du bon = 'lo que es vino, he bebido y del bueno'); y, en la forma algo (de), cuando el partitivo francés afecta a un adjetivo o un nombre concreto empleado en sentido abstracto o cuando va ante un nombre propio tomado en sentido ejemplar (il y a du sublime dans ce tableau = 'hay algo de sublime en este cuadro', il y a de la sainte en elle = 'hay algo de santa en ella', il y a du Don Juan en lui = 'hay algo de Don Juan en él').

${ }^{33} \mathrm{El}$ artículo partitivo siempre es la preposición de en occitano, sea cual sea el género y el número (de pan equivale al francés du pain, d'aigo / d'ayga equivale a de l'eau, etc.). 
$u r$-ik $=$ '[algo] de agua'). Está documentado con esas dos funciones de ablativo y de partitivo ya en los textos más antiguos, que son del siglo XVI (Michelena, 1964: 83; Azkarate y Altuna, 2001: 92-93). La función original de ablativo que tenía el sufijo -ik / -rik descartaría el origen vasco del caso partitivo, que no existiría en la primitiva EMN vasca ni tendría ningún sufijo característico en ella. Por el contrario, la utilización del caso ablativo vasco para expresar el partitivo es un calco del partitivo románico (francés $d u$ pain, de l'eau, des pommes; francés antiguo mangier de pain 'manger du pain', etc.), y principalmente occitano, que en gran parte de sus dialectos todavía utiliza la preposición de sin el artículo definido (de pan, d'aigo/d'ayga), exactamente igual que en vasco. Por ejemplo, ogi-rik = '[algo] de pan', al utilizar el caso ablativo como un calco del occitano, se hizo equivalente a Baiona-rik nator = "vengo de Bayona', y todavía lo sigue siendo en los dialectos septentrionales, en los que se sigue utilizando en la actualidad el sufijo -rik para expresar tanto el ablativo, que es su función original, como el partitivo.

La antigüedad del artículo partitivo románico permite aceptar esta relación con el artículo vasco, puesto que apareció en latín vulgar y luego se desarrolló y se ha conservado principalmente en occitano (Ronjat, 1937: 127-129; Jensen, 1986: 79-81), en francés (Menard, 1968: 19-20; Tritter, 1999: 32; Schejbalová, 2003) y en italiano, y mucho menos en castellano, catalán y gallego-portugués. La primera fase, documentada ya en latín vulgar, consistió en utilizar la preposición DE elidiendo la palabra PARTEM ${ }^{34}$, y así se generalizó en la Edad Media y se ha conservado hasta ahora en occitano ${ }^{35}$ y en alguna expresión francesa residual (como boire de bon vin 'beber buen vino' $)^{36}$. En una segunda fase, a la preposición de se le añadió el artículo determinado en francés y en algunos dialectos occitanos, completándose así el proceso desarrollado desde el latín vulgar ${ }^{37}$. La influencia

\footnotetext{
34 "A construction with de is not uncommon in Vulgar Latin; Nyrop (V§141) rates it as elliptic, with de depending on an unexpressed partem: date nobis de oleo vestro 'give us (some) of your oil'; sacrificare de animalibus 'sacrifice (some) animals'; dimidium de praeda 'half of the spoils', and he explains the corresponding Old French syntax in similar terms. The construction may have gained momentum in Gallo-Romance through the use of the preposition de following the adverbs of quantity" (Jensen, 1986: 80).

35 "There is documentation for an early stage of a partitive construction, consisting of the preposition $d e$ alone which, initially, appears only before the direct object: de pan [...], d'ayga [...]. Exemples of a full-fleged partitive article: $d e+$ definite article, are rare in Occitan: [...] $d e$ l'ayga, etc." (Jensen, 1986: 80).

36 “Quant à l'article dit 'partitif', il se traduit à l'origine par une absence de determinant. Petit à petit, vers les $\mathrm{XII}^{\mathrm{e}}-\mathrm{XIII}{ }^{\mathrm{e}}$ s., l'usage se répand d'utiliser la préposition de pour traduir l'idée partitive. C'est dire à que la solution moderne est en marche dès le Moyen Age, et que les formulations du type 'boire de bon vin' ne sont, à l'époque moderne, que des résidus en voie de disparition" (Tritter, 1999: 32).

37 “L'usage de la préposition de s'est développé à partir des tours du latin vulgaire (de pane edere 'manger du pain'; de vino bibere 'boire du vin'). Il s'est étendu en AF [ancien français], du
} 
románica, por tanto, estaría en el origen del caso partitivo vasco, que es un calco del occitano y del francés antiguo en esa primera fase de su desarrollo (con la preposición de sin el artículo determinado).

Por otra parte, al añadirle al sufijo de adlativo definido - $r a$ el sustantivo antz 'semejanza, semblante, cara', se formó el sufijo -rantz $\left(<*_{\text {-ra-antz }) \text { del }}\right.$ caso adlativo indefinido, por analogía con la expresión latina, castellana y altoaragonesa del tipo facie ad montem = 'cara al monte', en vez de ad montem versus $=$ 'hacia el monte' de los clásicos. La palabra vasca mendi-ta-rantz es en realidad su traducción literal. El sufijo -antz no aparece en los dialectos vascofranceses y ello puede estar relacionado con el hecho de que en francés, se emplea la preposición vers < VERSUS = 'hacia, del lado de', que es la del latín clásico, en lugar de hacia < FĂCĬES = "cara, fisonomía, semblante, forma, aspecto', que es la utilizada en castellano ${ }^{38}$. Por lo tanto, el caso adlativo indefinido habría aparecido solo en los dialectos vasco-españoles por influencia del castellano, ya que está indicado por un sufijo que es análogo a la preposición castellana que tiene su mismo significado ${ }^{39}$. Actualmente, el sufijo -rantz presenta numerosas variantes dialectales (-a-ntz, - $a-n t z-a,-r a-n t z,-r a-n t z-a,-r o-n t z$, $-r u-n t z,-r a-z,-r a-t z$ y $-r u-t z)$, a las que hay que añadir algunas con el artículo enclítico $(-r a-n t z-a)$ y la propia del adlativo definido -ra-t.

Sin embargo, el caso genitivo locativo sería anterior a la romanización y

fair que la préposition etait employée après les adverbes de quantité (molt de viande, poi de vin, auques de mal) et après la négation (je ne mange mie de paine). L'article partitif commence à être employé au MA [Moyen Age], pour désigner une quantité indeterminée d'une réalité indeterminée. Ansi, boire de l'ewe ne signifie pas seulment 'boire de cette eau dont il a été question plus haut' 'boire de cette eau qui vous appartient ou qui m'appartient', mais aussi tout simplement 'boire de l'eau"' (Menard, 1968: 20).

38 'HACIA, h. 1300 (faza, h. 1400). Contracción del cast. arcaico faze a 'de cara a', donde faze es la forma primitiva de $f a z$ 'rostro', procedente del lat. FACIES id. En el mismo sentido y en fecha más moderna se ha empleado cara a, s. XVI" (Corominas, 1990 [1961]: 313).

${ }^{39}$ R. M. de Azkue (1969 [1905-1906]: I, 333) atribuye a Ormaechea una explicación muy sugerente: "Es, en opinión de nuestro docto compañero, procedente de un nombre: antz "semejanza, semblante, cara". En pueblos del Alto Aragón dicen aún hoy "voy cara al monte" en vez de "voy hacia el monte". Esta misma preposición castellana 'hacia', en realidad no es otra cosa que 'cara', el latino facies. En latín vulgar, precursor del subdialecto aragonés, en vez de ad montem versus de los clásicos, decían facie ad montem, lit. ¿mendi-ra-antz?”. En efecto, antz = ‘semejanza' se utiliza en algunas localidades del dialecto occidental o vizcaíno y del dialecto central o guipuzcoano como "sufijo que se agrega a los nombres para denotar los colores no bien definidos" (Azkue, 1969 [1905-1906]: I, 47), esto es, el parecido o la semejanza; por ejemplo, or-antz = 'amarillento' = 'semejante al amarillo; baltze-rantz / beltze-rantz = 'negruzco' = 'semejante al negro'. Y antz más el artículo enclítico es antz- $a=$ 'la semejanza, el hedor, la habilidad', que explicaría posiblemente el sufijo -antza / -rantza con /a/ final. No sería extraño, pues, que se hubiera utilizado también como el "sufijo que denota el directivo indefinido en la declinación" (Azkue, 1905-1906, I: 48). Por lo tanto, el sufijo -rantz del caso ablativo idefinido se debió también a la influencia latino-románica, y es equivalente a la preposición de origen latino FACIES > hacia. 
pudo haber aparecido por influencia de la lengua celtibérica, que se hablaba al Sur y al Este de la lengua vasca limitando con ella. El sufijo de genitivo locativo -ko (Bilbo-ko = 'de Bilbao', etc.) es idéntico al sufijo indoeuropeo - $c o$ - utilizado en los gentilicios, que tiene su mismo significado y que se documenta abundantemente en las inscripciones celtibéricas de las áreas limítrofes (KaLAKoŔI-Ko-Ś = 'de Calagurris', KoNTeBa-Ko-M = 'los de Contrebia', ŚEKaISA-Ko-M = 'los de Segisa', AŔATi-Ko-Ś, LUTiA-Ko-Ś, etc.), por lo que este sufijo pudo aparecer en vasco por influencia de sus vecinos los celtíberos en los siglos anteriores a la romanización ${ }^{40}$. Puesto que $-k o$ es el único sufijo que existe del caso genitivo locativo, se puede pensar que este caso apareció al mismo tiempo que el sufijo que lo indica, como un caso de dicretismo de un antiguo caso genitivo común a las dos funciones ${ }^{41}$. El genitivo locativo empezó a utilizar el infijo -ta- en la EMN indefinida (etxe-ta-ko = 'de casa', frente a etxe-ko = 'de la casa', etc.), por analogía con los casos locativos (el indefinido etxe-ta- $n=$ 'en casa', que sustituyó al antiguo etxe- $n$, frente al definido etxe-a- $n=$ 'en la casa', etc.).

La $2^{\mathrm{a}}$ persona de respeto apareció en vasco utilizando el pronombre $z u$, que antiguamente significaba 'vosotros', concordando con la antigua $2^{\mathrm{a}}$ persona de plural de los verbos, de forma paralela a las lenguas románicas vecinas ${ }^{42}$ y como consecuencia de un fenómeno general en la Europa medieval. Pero en vasco se dio un paso más, y se creó una nueva $2^{\mathrm{a}}$ persona plural, $z u-e-k=$ 'vosotros/as', al añadirle el sufijo $-e$ (propio de la $3^{\mathrm{a}}$ persona plural) al pronombre $z u=$ 'vos' con el fin de distinguirlo de la $2^{\mathrm{a}}$ persona de respeto. Ya en la Edad Moderna, la generalización de $z u=$ 'vos' casi había suplantado al tuteo o tratamiento hika (de $i / h i=$ 'tú'), y por eso se empezó a utilizar el pronombre berori concordando con la $3^{\mathrm{a}}$ persona singular, de forma paralela al tratamiento cortés castellano vuestra merced, que apareció a finales del siglo XV y luego evolucionó a usted (vid. Castaños, 1979: 52 nota 9; Lapesa, 2000 [1970]: 316; Líbano, 1991: 113; Sánchez, 2001: 407-410; Penny, 1993: 138).

\footnotetext{
${ }^{40}$ En galo, también existía el sufijo -acos, que se latinizó como -acum y ha evolucionado al sufijo - $a c$, que actualmente forma parte de muchos topónimos franceses y occitanos.

${ }^{41}$ El genitivo locativo habría aparecido por dicretismo, distinguiéndose del genitivo posesivo, que siguió utilizando el sufijo -ren (Patxi-ren = 'de Patxi', etc.) o, mejor dicho, el antiguo sufijo -re, que se documenta en los textos más antiguos (Lope iaun Ortire semea $=$ 'el señor Lope hijo de Orti', en 1125, Mossen Bernat Echeparere cantuya = 'el canto de Mossen Bernat Echepare' en Dechepare, 1987 [1545]: XIII) y se conserva actualmente en los pronombres personales ( $g u$-re $=$ 'de nosotros, nuestro', zu-re $=$ 'de vosotros, vuestro', ni-re = 'mío', hi-re = 'tuyo', etc.). Ambos casos genitivos procederían de un antiguo genitivo común, que tendría las funciones de posesivo y de locativo. Esto permitiría entender la existencia en vasco de dos genitivos diferentes. Antiguamente, la $/ \mathrm{k} /$ se sonorizaba en $/ \mathrm{g} /$ detrás de $/ \mathrm{n} / \mathrm{y} / \mathrm{l} /$ hemen-go = 'de aquí', han-go = 'de allí'), pero después se empezó a añadir la vocal epentética /e/ detrás de consonante (por ejemplo, Irun-e-ko = 'de Irún', Burgos-e-ko = 'de Burgos').
} 
RECONSTRUCCIÓN DEL PROCESO DE FORMACIÓN DE LA EMN VASCA A PARTIR DE LA INFLUENCIA LATINO-ROMÁNICA

En resumen, toda la EMN plural se formó a partir de la introducción en vasco del sufijo abundancial latino -ĒTA, plural neutro de -ĒTUM. Primero se utilizó -eta- como sufijo derivativo abundancial en el léxico, después se declinó en los casos locativos, añadiéndole los sufijos casuales correpondientes a los lexemas con sufijo derivativo - eta, y finalmente se identificó la /e/ de -eta como sufijo de plural y se extiendió a los demás casos de los demostrativos primitivos ( $o$ y $a$ ). Estos, a su vez, se añadieron como artículos enclíticos a los lexemas para expresar la determinación (que el sutantivo al que acompañan ya es conocido) y formar así la EMN definida como un calco del artículo románi$\mathrm{co}^{43}$. Más tarde, el demostrativo de $3^{\text {er }}$ grado $a=$ 'aquel/aquella/aquello' se añadió en plural a los casos no locativos (los locativos ya tenían el sufijo - eta- y en el castellano medieval no utilizaban el artículo determinado), con la finalidad de expresar la pluralidad de los sustantivos, formando así la EMN de plural lejano, como un calco igualmente del artículo románico. Pero, en vasco, se llegó más lejos que en las lenguas románicas que le habían servido de modelo, y también se expresó el plural próximo, utilizando el antiguo demostrativo primitivo de $1^{\text {er }}$ y $2^{\circ}$ grado ( $o=$ 'este/esta/esto y ese/esa/eso'). Finalmente, tras identificarse la /e/ del sufijo - eta- como sufijo de plural - $e$-, el sufijo -ta- se identificó como sufijo indicador de los casos locativos inanimados y se añadió en los casos locativos inanimados de la antigua EMN indefinida. El sufijo -ta- solo se utilizó en los casos locativos, porque procedía del sufijo -eta-, que solo se utilizaba en dichos casos porque originalmente era un sufijo abundancial. Además, se utilizaba con mayor propiedad en los sustantivos inanimados, debido a ese significado abundancial original. Por eso, en los casos locativos de los sustantivos que no eran inanimados se tendió a utilizar otro sufijo distinto de -ta- para distinguirlos de los que eran inanimados. La partícula que se utilizó fue el sufijo -gan, relacionado por Azkue (1969 [1905-1906]: I, 323-324) con el sustantivo gain = 'cumbre, cima, altura, superficie, parte exterior', que se añadió de forma enclítica a los sustantivos definidos animados (con el artículo enclítico - $a$ ) para indicar inicialmente el caso inesivo, en vez de la terminación -ta- $n=$ 'en' de los inanimados, y después los demás casos locativos ${ }^{44}$. Según lo

42 "This form was also used for plural reference, and originates from Latin, where vōs was used as a plural form, but began to be used as a singular form to express politness and repect towards a singular interlocutor from the fifth century onwards, when the Roman empire had two emperors, each of whom was consequently addressed in the plural" (Jonge y Neuwenhuijsen, 2012: 252).

43 "La primera serie de procesos parece haber tenido lugar antes de que el artículo invadiese los casos locales" (Castaños, 1979: 58).

44 Ya Castaños (1979: 199) concluyó que, sobre "las primeras formaciones nominales de plural de expresión abierta con la incorporación de formas en -eta- a la declinación. Esto tiene lugar 
expuesto anteriormente, el proceso de formación de la EMN vasca actual constaría de las siguientes fases:

$1^{\text {a) }}$ El sufijo abundancial latino -ĒTA, plural neutro de -ĒTUM, se introduce en vasco por importación del latín antes de que se sonorizaran las oclusivas sordas intervocálicas en las lenguas románicas occidentales (antes del siglo v) y se empieza a utilizar para formar derivados con significado abundancial.

$\left.2^{a}\right)$ Los sustantivos derivados formados con sufijo abundancial latino -ĒTA se declinan solo en los casos locativos al añadírseles los sufijos casuales correspondientes (por ejemplo, de harri = 'piedra', se formó harri-eta = 'pedregal', y de aquí, harri-eta- $n=$ 'en el pedregal', harri-eta-ra = 'al pedregal', harri-eta$k o=$ 'del pedregal', etc.). Se forma así la primitiva EMN plural con el sufijo abundancial -eta- más los sufijos casuales y esta EMN se utiliza con todos los sustantivos y adjetivos inanimados vascos.

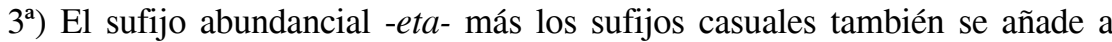
los dos demostrativos primitivos ( $o=$ 'este/esta/esto y ese/esa/eso'y $a=$ 'aquel/ aquella/aquello') para indicar la pluralidad y, por tanto, para formar la primitiva EMN plural de los mismos (genitivo locativo: o-eta-ko y a-eta-ko; inesivo: oeta-n y a-eta-n; ablativo: o-eta-ti-k / o-eta-ri-k y a-eta-ti-k / a-eta-ri-k; adlativo definido: o-eta-ra y a-eta-ra; adlativo indefinido: o-eta-ra-ntza / a-eta-ra-ntza; adlativo terminal: o-eta-ra-giño / a-eta-ra-giño). También se utiliza el caso ergativo singular para expresar el nominativo o absolutivo plural (*o-ga y $* a-g a)$.

$4^{\text {a) }}$ En los demostrativos, la /e/ del sufijo - eta- de los casos locativos se identifica como sufijo de plural lejano, por analogía con el demostrativo plural lejano enclítico - $e$ - (evolucionado a partir de $-a-e$-), que era el que realmente indicaba el plural cercano en los casos no locativos. También se pudo producir la analogía con el sufijo de plural - $e$ - de la estructura morfológica verbal (EMV) o conjugación, que distinguía la $3^{\mathrm{a}}$ persona plural de la $3^{\mathrm{a}}$ singular, ya que ambas personas compartían el mismo afijo personal (los prefijos personales $d$-, z- o $l$-, el morfema cero o el sufijo -o, según los tiempos verbales y los tipos de verbos). Así, los verbos pudieron concordar con los demostrativos también en la $3^{\text {a }}$ persona plural. La sílaba [ta] del sufijo - eta- se identificó, entonces, como sufijo propio de los casos locativos (genitivo locativo: o-e-ta-ko y

en los casos locales. Este elemento es, de acuerdo con Schuchardt, de origen latino y formaba en vasco, por lo general, topónimos abundanciales: Arrieta 'pedregal', Pagoeta 'hayedo'. El origen latino de -eta-, junto con otros indicios, determina los límites temporales de la creación del plural [...]. Otro segundo punto fundamental de la creación del sistema de declinación, tal como lo conocemos, es la interpretación de - eta- como -e-, morfema de plural, y -ta-, infijo local". Ahora confirmamos lo dicho anteriormente por Castaños, pero profundizando mucho más en el origen de la EMN plural y reconstruyendo totalmente el proceso. 
a-e-ta-ko; inesivo: o-e-ta-n y a-e-ta-n; ablativo: o-e-ta-ti-k / o-e-ta-ri-k y a-e-tati-k / a-e-ta-ri-k; adlativo definido: o-e-ta-ra y a-eta-ra; adlativo indefinido: $o$ e-ta-ra-ntza / a-e-ta-ra-ntza; adlativo terminal: o-e-ta-ra-giño / a-e-ta-ra-giño).

$\left.5^{a}\right)$ En los demostrativos, el nuevo sufijo de plural - $e$-, surgido de la /e/ del sufijo -eta- de los casos locativos, se añade también en todos los casos no locativos para formar el plural de los mismos, excepto en el nominativo plural, que utiliza el ergativo singular para expresar el plural como un procedimiento primitivo (ergativo: *o-e-ga y *a-e-ga; dativo: o-e-ri y a-e-ri; genitivo posesivo: $o$-e-re-n y a-e-re-n; destinativo: $o$-e-re-n-tza-t y a-e-re-n-tza-t;impulsivo: $o-e-r e-n-g a i-t i-k$ y a-e-re-n-gai-ti-k; sociativo: o-e-re-ki / o-e-ga-z y a-e-re-ki / $a-e-g a-z$; instrumental: $o-e-z$ y $a-e-z)$. La sílaba [ta] del sufijo -eta-, en cambio, no se añade porque se había identificado como sufijo propio de los casos locativos. Así quedaron formadas enteramente las dos declinaciones vascas de plural, tanto la de plural próximo y la de plural lejano.

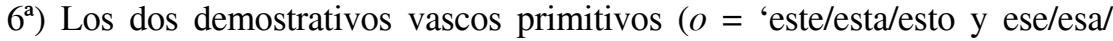
eso' y $a=$ 'aquel/aquella/aquello'), que se posponían a los sustantivos y adjetivos, se utilizaron como artículos determinados por influencia del romance, en el que el demostrativo de $3^{\text {er }}$ grado ya se había utilizado también como artículo determinado. Primero se utlizó el demostrativo vasco de $3^{\text {er }}$ grado $(a)$, igual que en romance y por analogía con él, pero después se utilizó también el antiguo demostrativo de $1^{\text {er }}$ y $2^{\circ}$ grado $(o)$. Se formó así la EMN determinada, que en un principio no distinguía el número y se utilizaba tanto en singular como en plural (nominativo o absolutivo: $-a$ y $-o$; ergativo: *-a-ga y *-o-ga; dativo: $-a$ ri y -o-ri; genitivo posesivo: -a-re-n y -o-re-n; destinativo: -a-re-n-tza-t y -o-re$n$-tza-t; impulsivo: -a-re-n-gai-ti-k y -o-re-n-gai-ti-k; sociativo: -a-re-ki / -a-ga$z$ y -o-re-ki / -o-ga-z; instrumental: $-a-z$ y $-o-z$; inesivo: $-a-n$ y $-o-n)$.

$\left.7^{a}\right)$ El plural del caso nominativo, absoluto o caso cero, se expresa mediante un procedimiento primitivo, que consiste en utilizar los sufijos $*_{-} a-g a>-a-k-\mathrm{y}$ $*_{-} o$ - $g a>-o-k$ - del caso ergativo singular, que pasan a utilizarse como sufijos abundanciales equivalentes a -eta, y por eso se utilizó y se ha conservado el sufijo - a-ga también en la toponimia.

$8^{\text {a }}$ ) Se forma la EMN plural de los sustantivos y adjetivos para poder establecer la concordancia con la EMV, ya que éstos se utilizaban en la $3^{\text {a }}$ persona en vez de los inexistentes pronombres de $3^{\text {a }}$ persona. Para que los dos demostrativos primitivos ( $o=$ 'este/esta/esto y ese/esa/eso' y $a=$ 'aquel/aquella/aquello') pudieran concordar con la $3^{\mathrm{a}}$ persona plural de los verbos, la /e/ del sufijo - eta- de los casos locativos de los demostrativos se identifica como sufijo de plural próximo y lejano, por analogía con el sufijo de plural - $e$ - de la EMV, que se utlizaba para distinguir la $3^{\mathrm{a}}$ persona plural de la $3^{\mathrm{a}}$ singular, ya que ambas compartían el mismo afijo personal (los prefijos $d-$, $z-$ o $l$-, el morfema cero o el sufijo $-o$, según los tiempos verbales y los tipos de verbos). En los 
demostrativos, se utilizaron procedimientos primitivos, como la utilización de una raíz diferente en singular y en plural de los casos oblicuos.

$9^{\text {a) }}$ El plural próximo y lejano de todos los demás casos (los no locativos) de la EMN, excepto el nominativo o absolutivo, también se expresó por medio de los demostrativos vascos primitivos ( $o=$ 'este/esta/esto y ese/esa/eso' y $a=$ 'aquel/aquella/aquello'), igual que en la nueva EMN determinada, pero en plural (con el sufijo - $e$-). Por lo tanto, el plural de los sustantivos y adjetivos vascos se formó al añadirle al lexema (el sustantivo o adjetivo) el demostrativo de $1^{\text {er }}$ y $2^{\circ}$ grado $o$ - o el demostrativo de $3^{\text {er }}$ grado en plural $a$ - más el sufijo de plural $-e$ - seguido de los sufijos casuales, es decir, con sus EMN respectivas.

\begin{tabular}{|c|c|c|c|c|c|c|}
\hline \multirow[t]{2}{*}{ Casos } & \multicolumn{3}{|c|}{ Singular } & \multicolumn{3}{|c|}{ Plural } \\
\hline & Indefinido & Defin. lej. & Def. cerc. & Primitivo & Definido lej. & Definido cerc. \\
\hline Nominativo o Absol. & & $-\mathrm{a}$ & -0 & & $-a--g a$ & $*_{\text {-o- }}-$-ga \\
\hline Ergativo (agente) & $*_{\text {-ga }}$ & $*_{\text {-a-ga }}$ & $*_{\text {-o-ga }}$ & & $*$-a-e-ga & *-o-e-ga \\
\hline Dativo ('a') & -ri & -a-ri & -o-ri & & $*_{\text {-a-e-ri }}$ & $*_{\text {-o-e-ri }}$ \\
\hline Genit. posesivo ('de') & -re & $*$-a-re & $*$-o-re & & $*_{\text {-a-e-re }}$ & $*_{\text {-o-e-re }}$ \\
\hline Sociativo (gen.) ('con') & -reki & -a-reki & $*_{\text {-o-reki }}$ & & $*_{\text {-a-e-reki }}$ & $*$-o-e-reki \\
\hline Sociativo (vizc.) ('con') & $-g a z$ & $-a-g a z$ & $*_{\text {-o-gaz }}$ & & $*_{\text {-a-e-gaz }}$ & $*_{\text {-o-e-gaz }}$ \\
\hline Instr. ('por medio de') & $-\mathrm{z}$ & $-a-z$ & $*_{-O-Z}$ & & $*_{\text {-a-e-z }}$ & $*_{-0-\mathrm{e}-\mathrm{z}}$ \\
\hline Genit. locativo ('de') & -ko & $-k o$ & $*$-ko & -eta-ko & *-a-eta-ko & $*_{\text {-o-eta-ko }}$ \\
\hline Inesivo ('en') & $-n$ & $-a-n$ & $*_{-o-n}$ & -eta-n & $*_{\text {-a-eta-n }}$ & $*_{\text {-o-eta-n }}$ \\
\hline Perlativo ('por') & $*_{\text {-tika }}$ & $*$-tika & $*$-tika & *-eta-tika & $*_{\text {-a-eta-tika }}$ & $*_{\text {-o-eta-tika }}$ \\
\hline Ablativo ('desde') & *-rika & $*_{\text {-rika }}$ & *-rika & *-eta-rika & $*_{\text {-a-eta-rika }}$ & $*_{\text {-o-eta-rika }}$ \\
\hline Adlativo defin. ('a') & *-ra & -ra & $*_{\text {-ra }}$ & -eta-ra & $*_{\text {-a-eta-ra }}$ & $*_{\text {-o-eta-ra }}$ \\
\hline Adlat. indef. ('hacia') & *-rantz & $*$-rantz & $*_{\text {-rantz }}$ & -eta-rantz & $*_{\text {-a-eta-rantz }}$ & $*_{\text {-o-eta-rantz }}$ \\
\hline Adlat. termin. ('hasta') & $*$-ragindo & $*_{\text {-ragindo }}$ & *-ragindo & -eta-ragindo & *-a-eta-ragindo & *-o-eta-ragindo \\
\hline
\end{tabular}

TABLA 1.-La Estructura Morfológica Nominal (EMN) antigua de la lengua vasca.

$10^{\mathrm{a}}$ ) Los artículos enclíticos vascos de las dos nuevas EMN de plural evolucionaron fonéticamente reduciendo las vocales en hiato mediante el $\mathrm{CF}=a e>$ $e$ y el $\mathrm{CF}=o e>o$, quedando reducidos a $-e$ - en la EMN del plural lejano y a -o- en la EMN del plural cercano, respectivamente ${ }^{45}$ (dativo: $*$-a-e-ri $>-e$-ri;

45 Estos cambios fonéticos (CF) cumplen las leyes fonéticas vascas y los dos primeros, además, son puestos como ejemplos de esos mismos $\mathrm{CF}$. Por lo que se refiere al $\mathrm{CF}=a e>e$, "el resultado normal de la contracción de $a+e$ y $a+o$ parece ser $e(a)$ y $o$, menos veces $a i, a u$. [...] Or. -ek, suf. de act. pl. (ronc. sul. -ék), de *-a-ek : occid. -ak, igual al de nom. pl. es común, en cambio, -en (ronc. sul. -én), de *-a-en, vizc. ant. -aen, -(e)en" (Michelena, 1985 [1961]: 117). Por 
$*_{-o-e-r i}>$-o-ri; *-a-e-ren > -e-ren; genitivo posesivo: *-o-e-ren > -o-ren; genitivo locativo: *-a-e-ta-ko >-e-ta-ko; *-o-e-ta-ko >-o-ta-ko; inesivo: *-a-eta-n>-e-ta-n; *-o-e-ta-n>-o-ta-n; etc.). Los casos locativos de la EMV de plural lejano se igualaron, entonces, con los de la antigua EMV indefinida con el sufijo abundancial -eta-, y solo se utilizaron en la EMV de plural lejano (*mendi-a-e-ta- $n>$ mendi-e-ta- $n$, *etxe-a-e-ta- $n>$ etxe-e-ta- $n$, etc.).

$\left.11^{a}\right)$ Como consecuencia de la evolución fonética de [oe], la EMN de plural cercano, caracterizada por el sufijo de plural - $O$ - procedente de $-o-e-$, se igualó a la EMN de singular cercano, que también se caracterizaba por el sufijo - o(que era el antiguo demostrativo de $1^{\text {er }}$ y $2^{\circ}$ grado enclítico). Sin embargo, el sufijo - $o$ - la EMN de plural cercano, resultante de la evolución fonética de - $o$ $e$ - más los sufijos casuales, se identificó como sufijo de plural cercano en todos los casos, de la misma manera que el sufijo - $e$-, evolucionado a partir de $-a-e-$, se había identificado con el sufijo el plural lejano (primero en los casos no locativos y, después, también en los locativos). Como consecuencia de ello, la EMN definida de singular cercano (con el sufijo -o) cayó en desuso y desapareció, y la EMN con sufijo -o- solo se conservó como EMN de plural cercano. A partir de entonces, en vez de la EMN de singular cercano (con sufijo -o-), se utilizó solo la EMN de singular lejano (con sufijo - $a$-) para los dos tipos de plural. La EMN de singular cercano, con sufijo -o, se mantuvo hasta el siglo XVII o XVIII en el nominativo o absolutivo singular (muskarr-o, çuurr-o/çuurr$a$, moç-o/motç-a, çaldun-o/çaldun-a, Hederr-o/Hederr-a, Sagarr-o/Sagarr-a/ Sagar, Gogorr-o, Hudal-o, Gorostapal-o, etc.; vid. Azkarate y Altuna, 2001: 41) porque era el único caso que no se confundía con el plural cercano, que utilizaba el sufijo -ok (<-oek). Se unificaron así las EMN de singular y plural cercano en una sola, que se utilizó solamente como EMN de plural cercano, con el sufijo - $\mathrm{o}^{-}$, siendo ese el origen de las dos EMN plurales actuales, la del plural cercano, con el sufijo - $O-$, y la de plural lejano, con el sufijo - $e$-.

$12^{\mathrm{a}}$ ) Como consecuencia de la identificación de la /e/ del sufijo -eta- como sufijo de plural y de su utilización con esa función en los casos no locativos, la sílaba /ta/ se identificó como sufijo indicador de los casos locativos de género inanimado porque solo existía en ellos, y por eso se añadió también en los casos locativos inanimados de la EMN indefinida primitiva. Por eso, ya en época muy tardía (a finales de la Edad Media o en la Edad Moderna), se añadió -taen los casos locativos de la EMN indefinida como un nuevo sufijo que indicaba los casos locativos del género inanimado. Por ejemplo, etxe- $n=$ 'en casa', que se ha documentado en suletino (Lafitte, 1944: 59), se convirtió en etxe-ta-n (Schuchardt, 1923: 46). Así se formaron los nuevos sufijos de los casos loca-

lo que se refiere al $\mathrm{CF}=o e>o$, "De $o$ más $e:$ com. -ok, -on<-oek, -oen, en la declinación del artículo próximo" (Michelena, 1985 [1961]: 120). 
tivos de la EMN indefinida (genitivo locativo: -ta-ko; inesivo: -ta-n; ablativo: -ta-ti-k / -ta-ri-k; adlativo definido: -ta-ra; adlativo indefinido: -ta-ra-ntza; adlativo terminal: -ta-ra-giño).

$13^{\mathrm{a}}$ ) Los demostrativos se tuvieron que distinguir de los artículos enclíticos para evitar que se confundieran con ellos, lo que se hizo añadiéndoles algún afijo en el caso nominativo, absoluto o caso cero, o bien en todos los demás casos. Este refuerzo de los demostrativos para distinguirse de los artículos enclíticos vascos de la EMN se puede resumir así (Domene, 2011: 143-163):

- En el demostrativo de $1^{\text {er }}$ grado, se utilizó como raíz el intensivo $a$ - $u<$ * $a$ - $o$ en nominativo singular y plural, y en todos los demás casos del plural, y el caso inesivo del antiguo demostrativo $o(o-n)$ en todos los demás casos del singular. El antiguo demostrativo $a$ se conserva en el dialecto occidental o vizcaíno y, con su antigua EMN, en los adverbios (h)an = 'allí', que es el caso inesivo, y ( $h$ )ara = 'allí (indicando movimiento)', que es el caso adlativo. Modernamente, se le añadió a $a u$ en los dialectos septentrionales una /r/ final (ha$u-r$ ) por analogía con la /r/ epentética del dativo y el genitivo posesivo.

- En el demostrativo de $2^{\circ}$ grado, se utilizó como raíz el antiguo $o=$ 'este, esta, esto' y 'ese, esa, eso', más una /r/ final (o-r), añadida posiblemente por analogía con la /r/ epentética del dativo y el genitivo posesivo, aunque esa [-r] también es común a otras palabras vascas como zer, nor, hirur frente a iru, laur frente a lau, etc. Los sufijos casuales se añadieron a la raíz orr-, con la /rr/ múltiple propia de la posición final absoluta que se conserva en el adverbio (h)or = 'ahí'. El mismo (h)o-r más el sufijo $-i$ de los adjetivos y participios ${ }^{46}$, esto es, or- $i$, se ha utilizado en nominativo singular y en todos los casos del plural. El primitivo demostrativo $o$ se conservó en la EMN hasta la Edad Moderna, y el antiguo demostrativo or se ha conservado en el adverbio ( $h$ )or $=$ 'ahí' y en la raíz (h)orr- de los casos oblicuos de la EMN singular del demostrativo de $2^{\circ}$ grado.

- En el demostrativo de $3^{\text {er }}$ grado, se utilizó como raíz el antiguo $a=$ 'aquel, aquella, aquello', que se ha conservado en el dialecto occidental o vizcaíno y en los casos del plural de todos los dialectos. Más tarde, se le añadió una /r/ final (a-r-) por analogía con la /r/ epentética del dativo y el genitivo posesivo (igual que en el demostrativo de $2^{\circ}$ grado $o$ - $r$-), y esta raíz ar- se utilizó en todos los casos del singular excepto el nominativo. En todos los dialec-

\footnotetext{
46 Según Trask (1995), el sufijo - $i$ era el que formaba los adjetivos en general y por ello formó también los participios verbales (Lakarra, 1995: 192). Así, por ejemplo, gorri = 'rojo' sería el adjetivo formado al añadirle el sufijo $-i$ al sustantivo gor = 'carne' (gorr $-i=$ 'encarnado'); $z$ uri $=$ 'blanco', al añadirle $-i$ al sustantivo $z u r=$ 'madera', berri $=$ 'nuevo', al añadirle $-i$ a ber $<$ bior, biur = 'torcido, curvo', que se utiliza como prefijo significando re- 'de nuevo'. Por analogía con los adjetivos formados con el sufijo $-i$, se formaron los participios de los verbos (Azkarate y Altuna, 2001: 191).
} 
tos menos en el occidental o vizcaíno, el antiguo demostrativo $a$ se sustituyó, solo en el caso nominativo o absolutivo, por la moderna raíz ( $h$ )ura, que podría ser el antiguo $a=$ 'aquél' precedido de $u r$, que a su vez podría proceder del moderno aur, = 'este, esta, esto' (*haur-a > hur-a). La [h-] inicial de los dialectos septentrionales (hura, hori, hau) sería protética, y por lo tanto moderna, al igual que la [k-] y la [g-] de sus variantes dialectales roncalesasalacenca (kura, kori, kau) y aezcoana (gura, gori, gau), respectivamente, igual que en los sufijos de origen románico -k-eria y -k-eta (Michelena, 1985 [1961]: 208-224).

$14^{\text {a }) ~ C o m o ~ c o n s e c u e n c i a ~ d e ~ e s t o s ~ c a m b i o s ~ m o r f o l o ́ g i c o s, ~ s e ~ p r o d u c e ~ l a ~ e v o-~}$ lución fonética que origina los sufijos casuales tal y como son en la actualidad. Desaparece la /a/ final del sufijo *-aga de los casos ergativo singular y nominativo o absolutivo plural, según ley fonética (Michelena, 1985 [1961]: 133-135), por falsa identificación con el artículo determinado enclítico ${ }^{47}$, y se ensordece la oclusiva sorda $/ \mathrm{g} /$ al quedar en posición final (por ejemplo, iturri-a-ga > *iturri-a-g $>$ iturri-a- $k=$ 'las fuentes', harri-a-ga $>$ *harri-a-g $>$ harri-a- $k$ 'las piedras', en nominativo plural, etc.), y así se originan los actuales sufijos de nominativo y ergativo $-a-k$, $-e-k$ y $-o-k$ (Michelena, 1985 [1961]: 235-238). En el plural del dativo y del genitivo posesivo, desapareció la /r/ intervocálica (-e$r i>-e-i$ y $-e-r e-n>-e-e-n$, respectivamente) y después se unificó la doble /e/ resultante $(-e-e-n>-e n)$; pero en suletino, lo que desapareció fue la /i/ final en dativo $(-e-r i>-e-r)$. Por ejemplo, *gizon-e-ren $>$ gizon-e-en $=$ 'de los hombres'; *gizon-e-ri > gizon-e-i / gizon-e-r = 'a los hombres'; etc.). En los demostrativos, la evolución fonética más antigua de los sufijos casuales fue la misma que en la EMN, y así, en el dialecto occidental o vizcaíno se documenta (vid. Castaños, 1979: 22-24) la variante intermedia aeen en el genitivo posesivo plural (*aeren $>$ aeen $>$ aen $=$ 'de aquellos, de aquellas'), análoga a los adverbios de lugar $a-n=$ 'allí' y $a$-ra = 'allí (indicando movimiento)'.

47 También desaparece la /a/ final del sufijo - antza del caso alativo indefinido como consecuencia de la falsa identificación de la [-a] final con el artículo determinado enclítico - $a$ (Michelena, 1985 [1961]: 133-135). Por ejemplo, *etxe-ra-ntza > etxe-ra-ntz = 'hacia la casa' (definido singular); *etxe-ta-ra-ntza > etxe-ta-ra-ntz = 'hacia casa' (indefinido); *etxe-e-ta-ra-ntza $>$ etxe-e-ta-ra-ntz = 'hacia las casas [aquellas]' (plural lejano); *txe-o-ta-ra-ntza > etxe-o-ta-ra$n t z=$ 'hacia las casas [estas o esas]' (plural cercano). En el caso adlativo terminal, el sufijo $*_{-} r a-$ gin-do evolucionó al actual -ra-iñ-o. 


\begin{tabular}{|c|c|c|c|c|}
\hline \multirow[t]{2}{*}{ Casos } & \multicolumn{2}{|c|}{ Singular } & \multicolumn{2}{|c|}{ Plural } \\
\hline & Indefinido & Definido & Lejano & Cercano \\
\hline Nominativo o Absolutivo & & $-\mathrm{a}$ & $-a-k$ & $-\mathrm{o}-\mathrm{k}$ \\
\hline Ergativo (agente) & $-\mathrm{k}$ & $-a-k$ & $-e-k$ & $-0-k$ \\
\hline Dativo ('a') & - -ri & -a-ri & $-e-i$ & $-0-\mathrm{i}$ \\
\hline Genitivo posesivo ('de') & -re-n & -a-re-n & $-e-n$ & $-o-n$ \\
\hline Determinativo ('para') & -re-n-tza-t & -a-re-n-tza-t & -e-n-tza-t & -o-n-tza-t \\
\hline Impulsivo ('por') & -re-n-gai-ti-k & -a-re-n-gai-ti-k & -e-n-gai-ti-k & -o-n-gai-ti-k \\
\hline Sociativo (general) ('con') & -re-ki & -a-re-ki & $-\mathrm{e}-\mathrm{ki}$ & -o-ki \\
\hline Sociativo (vizcaíno) ('con’) & -ga-z & -a-ga-z & -e-ga-z & $-0-g a-z$ \\
\hline Instrumental ('por medio de') & $-\mathrm{z}$ & $-a-z$ & -e-ta-z & $-o-t a-z$ \\
\hline Genitivo locativo ('de') & -ta-ko & -ko & -e-ta-ko & -o-ta-ko \\
\hline Inesivo ('en') & - ta-n & $-a-n$ & -e-ta-n & -o-ta-n \\
\hline Ablativo (meridion.) ('desde') & -ta-ti-k & $-\mathrm{ti}-\mathrm{k}$ & -e-ta-ti-k & -o-ta-ti-k \\
\hline Ablativo (septentr.) ('desde’) & -ta-ri-k & -ri-k & -e-ta-ri-k & -o-ta-ri-k \\
\hline Adlativo definido ('a') & -ta-ra & -ra & -e-ta-ra & -o-ta-ra \\
\hline Adlativo indefinido ('hacia') & -ta-ra-ntz & -ra-ntz & -e-ta-ra-ntz & -o-ta-ra-ntz \\
\hline Adlativo terminal ('hasta') & -ta-ra-iñ-o & -ra-iñ-o & -e-ta-ra-iñ-o & -o-ta-ra-iñ-o \\
\hline
\end{tabular}

TABLA 2.-La Estructura Morfológica Nominal (EMN) vasca actual del género inanimado.

$15^{\mathrm{a}}$ ) Tras estos cambios fonéticos antiguos, que son comunes a los demostrativos y a los sufijos nominales, los demostrativos ( $a$ y $o$ ) sigueron evolucionando fonéticamente de una manera distinta a los artículos determinados enclíticos (Castaños, 1979: 22-24). Esa evolución fonética no consistió en la reducción de los grupos vocálicos [oe] y [ae] en hiato a [o] y [e], respectivamente, como ocurrió en los demostrativos enclíticos que funcionaban como artículos determinados, sino en el mantenimiento de esos mismos grupos vocálicos [oe] y [ae], pero reforzando su estabilidad fonética mediante una /i/

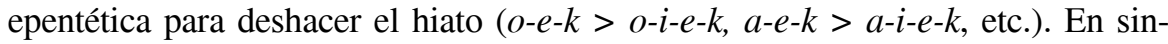
gular, los demostrativos se distinguieron del artículo determinado enclítico mediante la adición de una /r/ epentética por analogía con los casos que ya la tenían (el dativo y el genitivo posesivo). Por ejemplo, al añadirle la $/ \mathrm{r} /$ epentética a $a-k=$ 'aquel, aquella, aquello', se convirtió en $a-r-k$, por analogía con $a-r-i=$ 'a aquel, aquella, aquello' y con $a-r-e n=$ 'de aquel, aquella, aquello' y sus compuestos. También se ha utilizado el ergativo plural como nominativo plural 
(o-i-e-k, $a-i-e-k)$ y, además, se ha añadido en singular el sufijo -ta- en los casos locativos del singular. Así, por ejemplo, el demostrativo $a-n=$ 'en aquel, aquella, aquello' se ha conservado como adverbio 'allí', pero como demostrativo se convirtió en $a$-ta- $n$ y luego en $a$-r-ta- $n$, por analogía con $a$-e-ta- $n(<a-e t a-n)=$ 'en aquellos, aquellas' y los demás casos locativos.

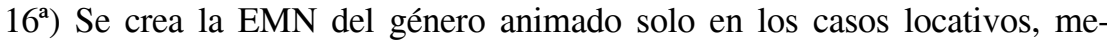
diante la utilización del sufijo - gan $^{48}$ como sufijo del caso inesivo (gizon-a-gan $=$ 'en el hombre', en el dialecto occidental o vizcaíno) y, tras él, se añadieron los demás sufijos propios de los casos locativos, que evolucionaron fonéticamente según las leyes fonéticas vascas. El sufijo - gan tenía la función de distinguir los seres animados de los inanimados (que tenían el sufijo -ta-, procedente de -eta) y se añadió al lexema en el caso nominativo definido en el dialecto occidental o vizcaíno (gizon-a-gan $=$ 'en el hombre', gizon-gan $=$ 'en hombre'), seguido de los demás sufijos locativos; pero en los demás dialectos meridionales (central o guipuzcoano y navarro) se añadió al lexema en el caso genitivo posesivo definido (gizon-a-ren gan = 'en el hombre'), es decir, se añadió al artículo enclítico -a-ren; finalmente, en los dialectos septentrionales (navarro-labortano y suletino) se añadió a la partícula bait, pospuesta a los sustantivos o adjetivos en genitivo posesivo (gizon-a-ren *bait-gan > gizon-a-ren bait-an = 'en el hombre'). En plural, en el dialecto occidental o vizcaíno y en el navarro, el sufijo gan, seguido de los demás sufijos de los casos locativos, se añadió al caso nominativo plural, es decir, al sufijo - ak, evolucionando detrás de él según las leyes fonéticas vascas (*gizon-ak-gan > gizon-ak-an = 'en los hombres'). Esta diversidad y el procedimiento utilizado indican su modernidad y la del género animado propiamente dicho, ya que -gan es posterior a la aparición del artículo enclítico en vasco y, por tanto, a la formación de la EMN definida ${ }^{49}$. El hecho de que el sufijo -ta-, propio del género inanimado, todavía se documente en

\footnotetext{
${ }^{48} \mathrm{La}$ formación de la EMN del género animado en los casos locativos consistió en la utilización del adverbio gain > -gan = 'encima de' como sufijo del caso inesivo, en el dialecto occidental o vizcaíno, unido al sustantivo o adjetivo en genitivo posesivo en guipuzcoano y navarro, y añadido a bait con el sustantivo o adjetivo en genitivo posesivo, en los dialectos septentrionales. Al sufijo enclítico gain > -gan se le añadieron los demás sufijos propios de los casos locativos. Teniendo en cuenta que en el dialecto occidental o vizcaíno se conserva la variante -gain- $a$ del caso alativo directivo en vez de la general -gan- $a$ en los casos locativos animados, el sufijo original de dichos casos sería el adverbio de lugar enclítico gain = 'encima' (vid. Trask, 1997: 203; Azkarate y Altuna, 2001: 120).

${ }^{49} \mathrm{La} / \mathrm{r} /$ de los sufijos casuales -ren, -ri y -ra era epentética y solo se añadía detrás de vocal para evitar el hiato (Domene, 2011: 131-157). Por eso, no existía detrás de consonante y no se añadió detrás de -gan (gizon-a-gan- $a=$ 'al hombre'; *gizon-ak-gan- $a>$ gizon-ak-an- $a=$ 'a los hombres'), igual que tampoco se añadió en genitivo y dativo plural (gizon-ak-en = 'de los hombres', gizon-ak-i = 'a los hombres'). Esta nueva EMN de plural es más moderna que la general, con sufijo - - -, y se podría explicar como una innovación surgida en Vizcaya o en el área de Pamplona y difundida a través de Álava.
} 
algunos casos en los pronombres personales en vez de -gan, y que esto sea normal en los textos antiguos para los demostrativos y los pronombres personales ${ }^{50}$, confirmaría la modernidad del sufijo - gan y del género animado en la EMN vasca y la mayor antigüedad de -ta-, que sería común a los dos géneros hasta la aparición de -gan. La EMN de los pronombres personales ha conservado un estado más antiguo que la de los sustantivos y adjetivos también en otros aspectos, como en el genitivo posesivo singular (el sufijo -re, en vez del más moderno -ren). En los adverbios, se ha conservado fosilizada la antigua EMN de los demostrativos sin -ta- ni -gan y, por tanto, anteriores a la incorporación de estos sufijos a los casos locativos ${ }^{51}$ (Castaños, 1979: 25; Domene, 2011: 143-163).

\begin{tabular}{||l||l|l|l||l|l|l||}
\hline \hline \multicolumn{1}{||l||}{ Casos } & \multicolumn{3}{|c||}{ Singular } & \multicolumn{3}{c||}{ Plural } \\
\hline & Vizcaíno & Guip., navarro & Dial. Septentrion. & Vizc., nav. m. & Guip., nav. sept. & Dial. Septentrion. \\
\hline \hline $\mathrm{In}$ & -a-gan & -aren gan & -aren bait-an & -ak-an & -en gan & -en bait-an \\
\hline $\mathrm{Ab}($ mer.) & -a-gan-di-k & -aren gan-di-k & -aren bait-an-di-k & -ak-an-di-k & -en gan-di-k & -en bait-an-di-k \\
\hline $\mathrm{Ab}($ sept.) & -a-gan-i-k & -aren gan-i-k & -aren bait-an-i-k & -ak-an-i-k & -en gan-i-k & -en bait-an-i-k \\
\hline $\mathrm{Al}_{\mathrm{d}}$ & -a-gan-a & -aren gan-a & -aren bait-an-a & -ak-an-a & -en gan-a & -en bait-an-a \\
\hline $\mathrm{Al}_{\mathrm{i}}$ & -a-gan-antz & -aren gan-antz & -aren bait-an-antz & -ak-an-antz & -en gan-antz & -en bait-an-antz \\
\hline $\mathrm{Al}_{\mathrm{t}}$ & -a-gan-a-iñ-o & -aren gan-a-iñ-o & -aren bait-an-a-iñn-o & -ak-an-a-iñn-o & -en gan-a-iñ-o & -en bait-an-a-iñ-o \\
\hline \hline
\end{tabular}

TABLA 3.-Diversidad dialectal de la EMN vasca del género animado en los casos locativos.

Por lo tanto, la influencia latina y románica ha sido fundamental en la historia de la lengua vasca, no solo en su conjugación o EMV (Domene, 2010), sino tambien en su declinación o EMN, ya que permite comprender la formación de la EMN definida y las dos EMN plurales vascas, tanto la de plural próximo como lejano, y la existencia del artículo enclítico vasco que las originó, así como los procesos ocurridos en ellas y en la antigua EMV indefinida a partir de la cual se formaron. Estos procesos diacrónicos han sido paralelos a los del latín vulgar y a los del romance, que eran las lenguas de prestigio, y

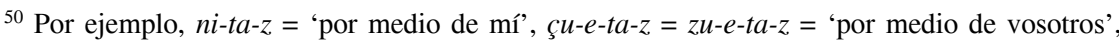
en el instrumental; $n i-t a-n=$ 'en mí', gu-ta- $n=$ 'en nosotros', çutan $=z u$-ta- $n=$ 'en vos' y çuetan $=z u-e-t a-n=$ 'en vosotros', en el inesivo; çuetara = zu-e-ta-ra = 'en vosotros', en el alativo; $n i$ ta-rik $=$ 'desde mí', çuetarik $=z u$-e-ta-rik = 'desde vosotros', en el ablativo; etc. (Castaños, 1979: 14-26).

${ }^{51}$ Los adverbios de lugar on- $a$ / hon- $a=$ 'aquí (indicando movimiento)', orr- $a$ / horr- $a$ = 'ahí (indicando movimiento)', $a-n / h a-n=$ 'allí' y $a-r a / h a r-a(t)=$ 'allí (indicando movimiento)', sin el sufijo - $t a$-, conservan la forma antigua de los demostrativos de los que proceden, mientras que los demostrativos actuales hon-ta-ra / hon-e-ta-ra = 'a este/esta/esto', hor-ta-ra / horr-e-ta-ra = 'a ese/esa/eso', ar-ta-n / har-ta- $n=$ 'en aquel/aquella/aquello' y ar-ta-ra / har-ta-ra(t) = 'a aquel/ aquella/aquello', que sí tienen el sufijo -ta-, incorporaron dicho sufijo posteriormente. 
habrían sido consecuencia de ellos. Ahora bien, a pesar de esta conexión general evidente, los detalles de su desarrollo particular en vasco resultan bien distintos de los románicos y no muestran sino la evolución notablemente autónoma del vasco respecto al romance en estos aspectos de la gramática. El método de reconstrucción interna es el que ha permitido conocer el proceso de formación de la EMN vascas y su evolución en sucesivas fases cronológicas a partir de la influencia latino-románica.

\section{BIBLIOGRAFÍA}

Altube, Sebero (1969 [1934]): Observaciones al "Tratado de morfología vasca" de Don R. M. de Azkue, $2^{\mathrm{a}}$ ed., Bilbao, La Gran Enciclopedia Vasca.

Alvar, Manuel y Bernard Pottier (1983): Morfología histórica del español, Madrid, Gredos.

Azkarate, Miren y Patxi Altuna (2001): Euskal morfologiaren historia, Donostia, Elkarlanean.

Azkue, Resurrección María de (1969 [1905-1906]): Diccionario vasco-español-francés, I-II, $2^{\text {a }}$ ed, Bilbao, La Gran Enciclopedia Vasca.

Azkue, Resurrección María de (1969 [1923-1925]): Morfología Vasca (gramática básica dialectal del euskera), Bilbao, La Gran Enciclopedia Vasca, tomos I, II y III.

Banniard, Michel (1995): "Ille et son système: chronologie du développement (IIIe-VIIIe s.)", en Louis Callebat (coord.), Latin vulgaire-Latin tardif IV: Actes $d u 4 e$ Colloque international sur le latin vulgaire et tardif, Hildesheim-Zürich-New York, Olms-Weidman, pp. 312-321.

Cano González, Ana María (1990): "Algunas observaciones sobre la diacronía del artículo", Revista de Filología Románica, 7, pp. 57-74.

Caro Baroja, Julio (1945): Materiales para una historia de la lengua vasca en su relación con la latina, Salamanca, Universidad de Salamanca.

Castaños Garay, Florentino (1979): La formación del plural en la lengua vasca, Bilbao, Publicaciones de la Diputación Foral del Señorío de Vizcaya.

Christol, Alain (1992): “Ipse: 'articloïde' ou article dans la Peregrinatio?”, Lalies, 13, pp. 143153.

Corominas, Joan (1990 [1961]): Breve diccionario etimológico de la lengua castellana, $3^{\mathrm{a}}$ ed, Madrid, Editorial Gredos.

Dechepare, Bernard (1987 [1545]): Linguae Vasconum Primitiae, Bilbao, Mensajero.

Domene Verdú, José Fernando (2007a): Lingüística y matemáticas: El proceso de formación de la estructura morfológica verbal de la lengua vasca, CD-ROM, Serie Tesis Doctorales, Leioa, Servicio de Publicaciones, Euskal Herriko Unibertsitatea / Universidad del País Vasco.

Domene Verdú, José Fernando (2007b): "El origen del afijo de plural -it-", Fontes Linguae Vasconum, 104, pp. 33-58.

Domene Verdú, José Fernando (2007c): "Los afijos temporales vascos", Fontes Linguae Vasconum, 105, pp. 189-217.

Domene Verdú, José Fernando (2007d): "Los modos impersonales del verbo vasco", Fontes Linguae Vasconum, 106, pp. 419-453.

Domene Verdú, José Fernando (2007e): "Matematización de la gramática y su aplicación a la estructura morfológica verbal de la lengua vasca", Estudios de Lingüística de la Universidad de Alicante (ELUA), 21, pp. 65-102.

Domene Verdú, José Fernando (2008a): "El verbo auxiliar trivalente de los dialectos navarro y central", Fontes Linguae Vasconum, 107, pp. 151-189. 
Domene Verdú, José Fernando (2008b): "El proceso de formación del alocutivo vasco", Fontes Linguae Vasconum, 108, pp. 329-364.

Domene Verdú, José Fernando (2009): Lingüística y Matemáticas. Axiomatización de la teoría gramatical y su aplicación a la tipología lingüística, Alicante, Publicaciones de la Universidad de Alicante.

Domene Verdú, José Fernando (2010): "La influencia tardo-latina en la lengua vasca: el origen tardo-latino de la estructura morfológica verbal analítica vasca a través de los verbos aditu y sortu", Revista de la Sociedad Española de Lingüística (RSEL), 40/1, pp. 49-72.

Domene Verdú, José Fernando (2011): La lengua vasca. Originalidad y riqueza de una lengua diferente, Alicante, Editorial Club Universitario.

Echenique, $\mathrm{M}^{\mathrm{a}}$ Teresa (1987): Historia lingüística vasco-románica, $2^{\mathrm{a}}$ ed., Madrid, Paraninfo.

Echenique, $\mathrm{M}^{\mathrm{a}}$ Teresa (1997): Estudios lingüísticos vasco-románicos, Madrid, Istmo.

Echenique, $\mathrm{M}^{\mathrm{a}}$ Teresa (2005): "La lengua vasca en la historia lingüística hispánica", en Rafael Cano Aguilar (coord.), Historia de la lengua española, $2^{\mathrm{a}}$ ed., Barcelona, Ariel, pp. 59-82

Echenique, $\mathrm{M}^{\mathrm{a}}$ Teresa y Juan Sánchez (2006): Las lenguas de un reino. Historia lingüística hispánica, Madrid, Gredos.

Frías Conde, Francisco Xavier (1993): "Los derivados de ille e illum en el gallego de Asturias", Revista de Filología Románica, 10, pp. 241-252.

Gavel, Henri (1920): Grammaire basque, Bayona, Le Courier.

Gil, Juan (2005): "El latín tardío y medieval (siglos VI-XIII)", en Rafael Cano Aguilar (coord.), Historia de la lengua española, $2^{\mathrm{a}}$ ed., Barcelona, Ariel, pp. 149-182.

Gimeno Menéndez, Francisco (2006): "Sociolingüística histórica: el proceso de formación de las lenguas románicas", en José Luis Blas Arroyo, Manuela Casanova Ávalos y Mónica Velando Casanova (eds.), Discurso y sociedad. Contribuciones al estudio de la lengua en contexto social, I, Castellón, Universitat Jaume I, pp. 33-80.

Gimeno Menéndez, Francisco y Claudio García Turza (2010): "La función social de los protorromances hispanos", en Francisco Gimeno Menéndez (coord.), Sociolingüística histórica sobre el proceso de formación de las lenguas romances, Aemilianense. Revista internacional sobre la génesis y los orígenes históricos de las lenguas romances, v. II, Logroño, CilenguaFundación San Millán de la Cogolla, pp. 127-202.

González Ruiz, José (1993): "La evolución de ille hasta la creación del artículo en las lenguas románicas", Actas del Congreso de la Sociedad Española de Lingüística, I, Madrid, Gredos, pp. 199-205.

Gordón Peral, María Dolores (2010): "Contribución al estudio de las hablas mozárabes. Sufijados en -etum en el romance primitivo del mediodía peninsular", Zeitschrift für romanische Philologie, 126, 3, pp. 460-479.

Gorrochategui, Joaquín (2009): "Vasco antiguo: algunas cuestiones de geografía e historia linguísticas", Acta Paleohispánica X. Actas do X colóquio sobre línguas e culturas paleohispânicas, Zaragoza, Institución "Fernando el Católico" / Excma. Diputación Provincial de Zaragoza / Centro de Estudos Arqueológicos das Universidades de Coimbra e Porto, Paleohispánica 9, pp. 539-555.

Herman, József (1997 [1975]): El latín vulgar, Barcelona, Ariel Lingüística.

Jensen, Frede (1986): The Syntax of Medieval Occitan, Tübingen, Max Niemeyer Verlag.

Jonge, Bob de y Nieuwenhuijsen, Dorien (2012): "Form of Address", en José Ignacio Hualde, Antxon Olarrea y Erin O'Rourke (eds.), The Handbook of Hispanic Linguistics, Oxford, Wiley-Blackwell, pp. 247-262.

Lafitte, Pierre Abbé (1995 [1944]): Gramaire basque (Navarro-labourdin litéraire), Donostia/ Baiona, Elkar.

Lafon, René (1995 [1943]): Le système du verbe basque au XVIème siècle, Elkar, Donostia / Baiona. 
Lakarra, Joseba Andoni (1995): "Reconstructing the pre-proto-Basque root", en José Ignacio Hualde, Joseba Andoni Lakarra y Robert L. Trask (eds.), Towards a History of the Basque Language, Amsterdam / Filadelfia, John Benjamins Publishing Company, pp. 189-206.

Lapesa, Rafael (1981[1942]): Historia de la lengua española, $9^{\mathrm{a}}$ ed., Madrid, Gredos.

Lapesa, Rafael (2000 [1961]): "Del demostrativo al artículo", en Estudios de morfosintaxis histórica del español, Rafael Cano Aguilar y $\mathrm{M}^{\mathrm{a}}$ Teresa Echenique Elizondo (eds.), Madrid, Gredos, pp. 360-387.

Lapesa, Rafael (2000 [1970]): "Personas gramaticales y tratamientos en español”, en Estudios de morfosintaxis histórica del español, Rafael Cano Aguilar y $\mathrm{M}^{\mathrm{a}}$ Teresa Echenique Elizondo (eds.), Madrid, Gredos, pp. 311-345.

Lapesa, Rafael (2000 [1979]): "Nominativo o caso oblicuo latinos como origen de demostrativos y artículo castellanos", en Estudios de morfosintaxis histórica del español, Rafael Cano Aguilar y $\mathrm{M}^{\mathrm{a}}$ Teresa Echenique Elizondo (eds.), Madrid, Gredos, pp. 346-359.

Lathrop, Thomas A. (1989 [1984]): Curso de gramática histórica española, $2^{\mathrm{a}}$ ed., Barcelona, Ariel.

Líbano Zumalacárregui, Ángeles (1991): "Morfología diacrónica del español: las fórmulas de tratamiento", Revista de Filología Española, 71, 1-2, pp. 107-122.

Lloyd, Paul M. (1993): Del latín al español. I. Fonología y morfología históricas de la lengua española, Madrid, Gredos.

Luján, Eugenio R. (2005): "Los topónimos en las inscripciones ibéricas", Acta Paleohispánica IX. Actas del IX coloquio sobre lenguas y culturas paleohispánicas, Zaragoza, Institución "Fernando el Católico" / Exma. Diputación Provincial de Zaragoza / Universitat de Barcelona, pp. 471-489.

Manterola, Julen (2006): "- $a$ artikulu definituaren gainean zenbait ohar", en Joseba Andoni Lakarra y José Ignacio Hualde (eds.), Studies in Basque and Historical Linguistics in Memory of $R$. L. Trask, Anuario del Seminario de Filología Vasca "Julio de Urquijo", 50, 1-2, Bilbao, UPV/EHU, pp. 651-676.

Menard, Philippe (1968): Manuel d'ancien français, 3, Syntaxe, Bodeaux, Sobodi.

Menéndez Pidal, Ramón (1987 [1904]): Manual de Gramática Histórica Española, 19ª ed., Madrid, Espasa-Calpe.

Menéndez Pidal, Ramón (2007 [2005]): Historia de la lengua española, ed. de Diego Catalán, $2^{\mathrm{a}}$ ed., Madrid, Fundación Ramón Menéndez Pidal.

Michelena, Luis (1964): Textos arcaicos vascos, Madrid, Minotauro.

Michelena, Luis (1985 [1961]): Fonética histórica vasca, $3^{\text {a }}$ ed., Diputación Foral de Guipúzcoa, Donostia-San Sebastián.

Michelena, Luis (1987 [1974]): "El elemento latino-románico en la lengua vasca", en Palabras y textos, Vitoria, Universidad del País Vasco, pp. 195-219.

Mondéjar, José (1985): "La función sintáctica como determinante de la estructura de dos categorías gramaticales: el artículo y el pronombre”, Revista Española de Lingüística, 15, 2, pp. 291-308.

Nieto Ballester, Emilio (1999): "Quelques notes sur les collectifs latins en -ÇTUM, -ÇTA dans la toponymie des langues espagnoles", en Hubert Petersmann y Rudolf Kettemann (coord.): Latin vulgaire-Latin tardif V: Actes $d u$ Ve Colloque international sur le latin vulgaire et tardif, Heildelberg, Universitätverlag C. Winter, pp. 312-321.

Orlandini, A. (1992): "La référence définie: la naissance dans les langues romanes de l'article défini à partir du démonstratif ILLE", Lalies, 11, pp. 195-210.

Penny, Ralph (2006 [1993]): Gramática histórica del español, 2a ed., Barcelona, Ariel.

Pensado Ruiz, Carmen (1984): Cronología relativa del castellano, Salamanca, Ediciones de la Universidad de Salamanca.

Rodríguez Pantoja, Manuel (2005): "El latín hablado en Hispania hasta el siglo V”, en Rafael Cano Aguilar (coord.), Historia de la lengua española, $2^{\mathrm{a}}$ ed., Barcelona, Ariel, pp. 107-132. 
Quilis, Antonio (2003): Introducción a la historia de la lengua española, Madrid, UNED.

Ronjat, Jules (1937): Grammaire historique des parlers provençaux modernes, Montpellier, Société des langues romanes.

Sánchez Lancis, Carlos E. (2001): "Historia de la lengua, gramática histórica y periodización en español", Estudi General 21, pp. 395-414.

Schejbalová, Zdeòka (2003): L'évolution des fonctions de l'article partitif en francais, $\mathrm{n}^{\circ} 1, \mathrm{Brno}$, Masarykova univerzita $v$ Brnì.

Schuchardt, Hugo (1922): "Heimisches und fremdes Sprachgut", Revista Internacional de Estudios Vascos, XIII, Paris / San Sebastián, pp. 69-82.

Schuchardt, Hugo (1947 [1923]): Primitiae Linguae Vasconum. Einführung ins Baskische, Universidad de Salamanca, Salamanca.

Spevak, Olga (2008): "Le placement de IS, HIC et ILLE chez Grégoire de Tours", en Roger Wright (coord.), Latin vulgaire-Latin tardif, VIII. Actes du VIII Colloque international sur le latin vulgaire et tardif, pp. 361-370.

Tovar, Antonio (1950): La lengua vasca, San Sebastián, Boletín de la Real Sociedad Vascongada de Amigos del País.

Torrens Álvarez, María Jesús (2007): Evolución e historia de la lengua española, Madrid, Arco/ Libros.

Trask, Robert L. (1995): "On the history of the non-finite verb forms in Basque", en José Ignacio Hualde, Joseba Andoni Lakarra y Robert L. Trask (ed.), Towards a History of the Basque Language, Amsterdam / Filadelfia, John Benjamins Publishing Company, pp. 207-234.

Trask, Robert L. (1997): The History of Basque, London / New York, Routledge.

Tritter, Jean-Louis (1999): Histoire de la langue française, Paris, Ellipses.

Väänänen, Veikko (1988 [1968]): Introducción al latín vulgar, 3ª ed., Madrid, Gredos.

Fecha de recepción: 19 de octubre de 2012

Fecha de aceptación: 17 de mayo de 2013 